\title{
SMART AND ILLICIT: \\ WHO BECOMES AN ENTREPRENEUR AND DO THEY EARN MORE?
}

\author{
Ross Levine \\ Yona Rubinstein \\ Working Paper 19276 \\ http://www.nber.org/papers/w19276
NATIONAL BUREAU OF ECONOMIC RESEARCH
1050 Massachusetts Avenue
Cambridge, MA 02138

August 2013

Previously circulated as "Smart and Illicit: Who Becomes an Entrepreneur and Does it Pay?" We thank Gary Becker, Moshe Buchinsky, David De Meza, Stephen Durlauf, Christian Dustmann, Luis Garicano, Naomi Hausman, Erik Hurst, Chinhui Juhn, Ed Lazear, Gustavo Manso, Casey Mulligan, Raman Nanda, Ignacio Palacios-Huerta, Steve Pischke, Luis Rayo, Andrei Shleifer, Chris Stanton, John Sutton, Ivo Welch, Noam Yuchtman, and seminar participants at the American Economic Association meetings, Asia Bureau of Financial and Economic Research, Harvard Business School, IDC, London School of Economics, NBER Summer Institute, NYU, Simon Fraser University, University of California-Berkeley, University of Chicago, University College-London, UCLA, University of Minnesota, and Victoria University of Wellington for helpful comments. Rubinstein thanks STICERD for financial support. The views expressed herein are those of the authors and do not necessarily reflect the views of the National Bureau of Economic Research.

NBER working papers are circulated for discussion and comment purposes. They have not been peerreviewed or been subject to the review by the NBER Board of Directors that accompanies official NBER publications.

(C) 2013 by Ross Levine and Yona Rubinstein. All rights reserved. Short sections of text, not to exceed two paragraphs, may be quoted without explicit permission provided that full credit, including $\mathbb{C}$ notice, is given to the source. 
Smart and Illicit: Who Becomes an Entrepreneur and Do They Earn More?

Ross Levine and Yona Rubinstein

NBER Working Paper No. 19276

August 2013,Revised September 2015

JEL No. G32,J24,J3,L26

\begin{abstract}
$\underline{\text { ABSTRACT }}$
We disaggregate the self-employed into incorporated and unincorporated to distinguish between "entrepreneurs" and other business owners. We show that the incorporated self-employed and their businesses engage in activities that demand comparatively strong nonroutine cognitive abilities, while the unincorporated and their firms perform tasks demanding relatively strong manual skills. The incorporated selfemployed have distinct cognitive and noncognitive traits. Besides tending to be white, male, and come from higher-income families, the incorporated - as teenagers - typically scored higher on learning aptitude tests, had greater self-esteem, and engaged in more disruptive, illicit activities. The combination of "smart" and "illicit" tendencies as youths accounts for both entry into entrepreneurship and the comparative earnings of entrepreneurs. In contrast to past research, we find that entrepreneurs earn more per hour and work more hours than their salaried and unincorporated counterparts.
\end{abstract}

\author{
Ross Levine \\ Haas School of Business \\ University of California at Berkeley \\ 545 Student Services Building, \#1900 (F685) \\ Berkeley, CA 94720-1900 \\ and NBER \\ Ross_levine@haas.berkeley.edu \\ Yona Rubinstein \\ Department of Management \\ London School of Economics \\ London \\ United Kingdom \\ y.rubinstein@lse.ac.uk
}




\section{Introduction}

Economists since Adam Smith (1776) have emphasized that entrepreneurs spur improvements in living standards. For example, Schumpeter (1911) argued that entrepreneurs drive economic growth by creating and introducing new goods, services, and production processes that displace old businesses. And, in models of the allocation of talent by Lucas (1978), Baumol (1990), Murphy, Shleifer, and Vishny (1991), and Gennaioli et al. (2013), entrepreneurs play a unique role in shaping the productivity of firms and hence the growth rate of entire economies.

Yet, a substantial body of research—using data on the self-employed to draw inferences about entrepreneurship—concludes that entrepreneurs do not earn more than their salaried counterparts (e.g., Borjas and Bronars (1989), Evans and Leighton (1989), and Moskowitz and Vissing-Jorgensen (2002)). For example, Hamilton (2000) finds that the median self-employed individual has lower initial earnings and slower earnings growth than those of a salaried worker with the same observed traits. To account for entry into self-employment, therefore, research points to (a) the non-pecuniary benefits of self-employment, such as being "one’s own boss" (Hurst and Pugsley 2011), (b) the fat right tail of the self-employment earnings distribution, and (c) the "over confidence" of entrepreneurs, as stressed by Bernardo and Welch (2001) and De Meza and Southey (1996).

Beyond earnings, little is known about who becomes an entrepreneur and what is known is puzzling. For Schumpeter (1911), entrepreneurs are “disruptive” economic leaders who take risks and break from routine. For Lucas (1978), Baumol (1990), Murphy, Shleifer, and Vishny (1991), and Gennaioli et al. (2013), entrepreneurs have unique skills that influence productivity, innovation, and growth. Yet, as we document below, the self-employed look ordinary. The average self-employed business owner and salaried worker have similar education, aptitude scores, and family backgrounds. If the self-employed are a good proxy for "growth-creating entrepreneurs," it is puzzling that their cognitive and noncognitive traits are similar to those of salaried workers and that they earn less.

Perhaps, self-employment is not a good proxy for entrepreneurship. Glaeser (2007) argues that self-employment aggregates together different types of activities and individuals, making "little distinction between Michael Bloomberg and a hot dog vendor.” While some of the self- 
employed are creative economic leaders who mobilize resources for distinctive ventures, others engage in qualitatively different business activities that deliver routine services. For instance, Evans and Leighton (1989) argue that in the United States many self-employed are one-person retail business owners who did not succeed as salaried workers. Gennaioli et al (2013) and La Porta and Shleifer (2008) find in a large cross-section of countries that many of the self-employed run low-productivity, commonplace businesses. They are not Schumpeterian entrepreneurs. Thus, studying the self-employed in general might yield misguided inferences about entrepreneurs in particular.

In light of these concerns about the gap between the conception and measurement of entrepreneurship, we first offer a new empirical proxy for entrepreneurship and show that it is closely aligned with the Schumpeterian view of entrepreneurship. Specifically, we disaggregate the self-employed into the incorporated and unincorporated and discover that on average (a) the incorporated engage in the types of entrepreneurial activities emphasized by Schumpeter, while the unincorporated do not and (b) the incorporated open different types of businesses from those owned by the unincorporated self-employed. To do this, we use the U.S. Department of Labor's Dictionary of Occupational Titles to document that the incorporated self-employed and their businesses engage in activities demanding a high degree of nonroutine cognitive skills, such as (a) creativity, analytical flexibility, and generalized problem-solving and (b) complex interpersonal communications such as persuading, selling, and managing others. We view these skills as closely aligned with the Schumpeterian conception of entrepreneurship. In contrast, we find that unincorporated business owners engage in activities, and open businesses, that demand notably low-levels of these cognitive skills and instead demand high-levels of eye, hand, and foot coordination, e.g., landscaping, truck driving, and carpentry. Strong manual skills are not defining features of the Schumpeterian view of entrepreneurship.

Our finding that business owners engaged in nonroutine, innovative activities tend to select the incorporated business form is consistent with the history and legal characteristics of corporations. Over several centuries, people created and honed the two defining legal characteristics of the incorporated business-limited liability and a separate legal identity (Harris 2000). Limited liability increases the appeal of purchasing equity in higher-risk projects. The 
separate legal identity reduces the likelihood that shocks to individual owners will disrupt the firm's activities, because it is the corporation that owns property and enters into contracts with workers, suppliers, and clients, not the individual owners. Not all businesses, however, will choose to incorporate. There are direct costs of incorporation, such as annual fees and the preparation of more elaborate financial statements, and indirect agency costs associated with the separation of ownership and control. Therefore, when people start businesses engaged in more routine activities that do not benefit much from limited liability or having a separate legal identity, they are more likely to select the unincorporated business form; and, when people start businesses engaged in more novel, innovative, and risky endeavors_-for which limited liability and the separate legal identity can play more supportive roles - the incorporated business form will tend to be more appropriate. From this perspective, the choice of the legal form of the business reflects the nature of the planned business activity.

Consistent with this view, we find that businesses seldom change their legal form: Unincorporated businesses rarely incorporate and incorporated businesses rarely become unincorporated sole proprietorships or partnerships. Although there might be concerns that successful unincorporated businesses eventually incorporate, this happens infrequently. In our sample, we find that only $15 \%$ of the incorporated self-employed switched the legal form of their business from unincorporated to incorporated. The evidence suggests that the choice of creating an incorporated or unincorporated business generally reflects the planned business activity, not it's ex post performance.

Using our proxy of entrepreneurship, we then ask: who becomes an entrepreneur and do they earn more? We use the March Supplements of the Current Population Survey (CPS) and the National Longitudinal Survey of Youth, 1979 (NLSY79). Although the CPS was not designed as a longitudinal study, we match individuals across time to create a two-year panel. This allows us to control for individual effects in assessing the change in earnings associated with a person who switches into or out of entrepreneurship. Although the NLSY79 surveys fewer individuals than the CPS, it has two advantages. First, it traces individuals from when they were teenagers or young adults in 1979 through 2012. Second, the NLSY79 has information on cognitive and noncognitive traits before individuals become prime age workers, including data on learning aptitude, 
personality traits, and the degree to which the individual engages in illicit activities. This provides insights on who becomes an entrepreneur-and who succeeds as one.

We find strong sorting into employment types based on cognitive and noncognitive traits. The incorporated tend to be white, male, more educated, and more likely to come from highearning, well-educated, two-parent families than salaried workers. Even as teenagers, those who incorporate later in life tend to score higher on learning aptitude tests, exhibit greater self-esteem, and engage in more illicit activities than other people. The unincorporated are very different. Although those who become unincorporated business owners also tend to engage in more illicit activities as youths than salaried workers, the unincorporated do not score higher on learning aptitude tests.

Moreover, it is a particular mixture of pre-labor market traits that is most powerfully associated with entrepreneurship. People who both engage in illicit activities as teenagers and score highly on learning aptitude tests have a much greater tendency to become incorporated selfemployed business owners than others. It is the particular mixture of "smart" and "illicit" characteristics that accounts for sorting into incorporated self-employment. Taken together, these findings on who becomes an entrepreneur are very consistent with the Schumpeterian conception of entrepreneurship. To create and introduce novel products under risky and uncertain conditions and "destroy" the positions of incumbent firms, it is unsurprising that the Schumpeterian entrepreneur is self-confident, smart, and prone to challenging convention.

These findings on the self-sorting of individuals into different employment types based on pre-labor market traits further highlight the usefulness of disaggregating the self-employed into incorporated and unincorporated business owners. We find that people with smart and illicit traits as youths who later run incorporated businesses are more likely to run businesses in industries demanding workers with high levels of creative thinking, analytically advanced problem solving, and strong communication skills. But, people with smart and illicit traits as youths who instead run unincorporated businesses are not more likely to run firms in industries that demand such strong nonroutine cognitive from their workers. Thus, even among "smart and illicit” business owners, the choice of the legal form of the business provides information about the nature of their business. 
We next examine earnings. Previous studies show that the typical self-employed business owner earns less than the typical salaried worker and conclude that entrepreneurship is associated with lower earnings. We make two contributions. First, rather than studying the aggregate group of self-employed, we distinguish between the incorporated-who are a better proxy for Schumpeterian entrepreneurs — and other business owners. Second, we use panel data to address key selection challenges associated with determining whether an individual earns more when becoming an incorporated or unincorporated business owner. In our examination of earnings, we do not evaluate the impact of randomly making somebody a business owner. We examine what happens to earnings when a person chooses to become self-employed.

Using data from both the CPS and the NLSY79, we find both that (a) the incorporated selfemployed earn much more per hour and work many more hours than comparable salaried workers and (b) the unincorporated self-employed earn much less. Consistent with our findings on who becomes an entrepreneur, much of the earnings gap, especially between incorporated business owners and salaried workers, reflects person-specific influences. Nonetheless, there is a large, additional boost in earnings when individuals switch into incorporated self-employment. For example, the mean residual annual earnings of an individual who switches from a salaried job to become an incorporated business owner rise by 18\% (relative to salaried workers) after accounting for individual effects. Comparing this estimate with the estimated earnings gap without fixed effects (52\%), the results show that people who become incorporated business owners were very successful salaried workers i.e., they were earning about 34\% more as salaried workers than other salaried workers with the same observable traits who do not become incorporated business owners. The results are very different for the unincorporated self-employed, who tend to be comparatively unsuccessful salaried workers. We believe this is the first paper to show that (a) unincorporated business owners tend to be comparatively unsuccessful salaried workers, (b) entrepreneurs tend to be relatively successful salaried workers, and (c) people who choose to become entrepreneurs tend to enjoy a sizeable increase in earnings beyond their high incomes as salaried workers.

Since people can select into and out of incorporated self-employment, this might raise concerns with these results. For example, if people choose to establish incorporated businesses when they have a very promising business idea and become unincorporated business owners when 
the expected gains are smaller, then the change in earnings might not reflect the entrepreneurial nature of the planned business activity. Similarly, if people try out their business idea in the form of an unincorporated enterprise and then incorporate if the business succeeds, then the estimated change in earnings will not accurately measure the change in earnings from becoming an entrepreneur. Our findings, summarized above, that incorporated business owners and their workers engage in qualitatively different activities (nonroutine cognitive) from those of unincorporated businesses (manual dexterity) suggest that such selection issues are not large. Nevertheless, we directly analyze switching across self-employment types.

We examine selection into and out of incorporated self-employment by exploiting the panel nature of the NLSY79. We study self-employment spells, where a self-employment spell is the full set of consecutive years that a person is self-employed. We find that there is some positive selection into incorporated self-employment based on success as an unincorporated business owner. As reported above, only 15\% of people who complete a self-employment spell as an incorporated business owner began the spell as unincorporated. Furthermore, although these switchers tend to be the successful unincorporated business owners, they do not materially affect the estimated increase in earnings associated with an individual becoming an incorporated selfemployed business owner. We also find very little switching across self-employment spells. About half of the people in the NLSY79 sample have multiple self-employment spells. Of these, 84\% are either incorporated or unincorporated in all of their spells. Moreover, when we classify all of an individual's self-employment observations as either incorporated or unincorporated using the first year of the first self-employment spell, all of the results hold. Finally we find evidence that business owners exercise the option to quit when the business is unsuccessful. Yet, the effect on the estimated increases in earnings is small. In sum, our results on earnings help account for the puzzle concerning the negative returns to self-employment: the incorporated earn more than salaried workers, the unincorporated earn less, and there are more unincorporated than incorporated individuals.

We next link these results on earnings with the earlier examination of who becomes an entrepreneur and discover that many of the same cognitive and noncognitive traits that explain selection into entrepreneurship also account for success as an entrepreneur. People with both high 
AFQT and high illicit scores as youths tend to experience much larger increases in earnings when they become incorporated self-employed business owners than people without that combination of traits. Yet, this combination of "smart and illicit" traits is associated with smaller earnings for unincorporated business owners. While past research shows the importance of noncognitive traits for labor market outcomes (Bowles et al. 2001; Heckman and Rubinstein, 2001; Heckman et al. 2006; Heckman, 2000), we document that some mixtures of traits receive positive or negative remuneration depending on the activity.

We close the paper with an examination of the distribution of earnings. Previous works shows that the self-employed have a much wider dispersion of earnings than salaried workers, suggesting that self-employment is risker. We first confirm that this result holds when separately examining incorporated and unincorporated self-employed: both have a wider dispersion of earnings than salaried employees. For example, the quantile analyses indicate that exceptionally successful incorporated business owners $\left(90^{\text {th }}\right.$ percentile) tend to earn almost $\$ 95,000$ more per annum than exceptionally successful salaried workers. Second, we show that much of this extra dispersion reflects person specific effects, not the extra gains and losses associated with business ownership. Third, after accounting for individual effects, the estimated earnings of the incorporated self-employed are greater than those of comparable salaried workers at each decile of the earnings distribution. Finally, our estimates indicate that the coefficient of variation in earnings is $60 \%$ greater when a person is an incorporated business owner than when he is a salaried worker. This is smaller than a similar comparison of the coefficient of variation on the S\&P 500 and Treasury Bills.

The paper is organized as following. Section II presents that data and summary statistics. Section III relates the Schumpeterian conception of entrepreneurship to the different tasks performed by incorporated and unincorporated business owners and their employees. We study who becomes an entrepreneur and whether they earn more in Sections IV and V respectively. Section VI concludes. 


\section{Data and Summary Statistics Across Employment Types}

We use three sets of data to (1) assess whether the incorporated self-employed perform activities — and run businesses — that fit the Schumpeterian conception of entrepreneurship while the unincorporated self-employed perform tasks and open businesses that are qualitatively different, (2) examine the sorting of individuals based cognitive and noncognitive traits into different employment types_-as measured by salaried, unincorporated self-employed, and incorporated self-employed types_-and different business activities_-as measured by routine and nonroutine activities, and (3) evaluate earnings following the self-sorting of people into employment types.

\section{A. CPS: Data and summary statistics on labor market outcomes and demographics}

We use the March Annual Demographic Survey files of the CPS for the work years 1995 through 2012. We start in 1995 because (a) the measure of incorporation changed following the redesign of the CPS in 1994 (Hipple 2010), (b) the CPS improved its top-coding in work year 1995 by allowing for differences across classes of workers and demographics, and (c) the post1995 period corresponds closely to the relevant years from the NLSY79. For the summary statistics, we include prime age workers (25 - 55 years old) who do not live within group quarters, have missing data on relevant demographics, or work in agriculture or the military.

The CPS classifies all workers in each year as either salaried or self-employed, and among the self-employed, indicates whether individuals are incorporated or unincorporated. Specifically, individuals are asked about their employment class for their main job: "Were you employed by a government, by a private company, a nonprofit organization, or were you self-employed (or working in a family business)?” Those responding that they are self-employed are further asked, “Is this business incorporated?”1 In terms of occupation, about half of the incorporated selfemployed are managers and no other three digit occupation accounts for more than $3.5 \%$ of the

\footnotetext{
${ }^{1}$ The core distinction in the survey is between unincorporated businesses, such as sole proprietorships and partnerships, and incorporated businesses. The CPS and NLSY79 provide self-reported classifications based on this coarse distinction. With respect to legal and tax definitions, there are many types of corporations and hybrid institutions. Most typically, C corporations are taxed separately from their owners. S corporations have no more than 100 shareholders and all income is passed through to shareholders for tax purposes. In terms of hybrid institutions, there are limited liability limited partnerships, limited liability partnerships, limited partnerships, etc.
} 
incorporated self-employed. Physicians and surgeons (3.3\%), lawyers (3.3\%), and accountants (1.3\%) combine to account for less than $8 \%$ of incorporated self-employment. With respect to the unincorporated, about 25\% are managers. Carpenters (9.2\%), truck drivers (4.6\%), and automobile mechanics (3.5\%) combine to account for about $17 \%$ of unincorporated self-employment.

We also construct a two-year matched panel. The CPS interviews a household for four consecutive months. The next year, the CPS returns to the same location. In most cases, the second interview involves the same household as the first interview. We follow the guidelines in Madrian and Lefren (2000) for matching CPS households across time. This involves checking the age, race, gender, education, etc. of those interviewed.

Panel A of Table 1 provides summary statistics from the CPS on the age, race, gender, education, and labor market outcomes of individuals reported as working while distinguishing among salaried workers, all self-employed workers, the unincorporated self-employed, and the incorporated self-employed. Hourly earnings are defined as real annual earnings divided by the product of weekly working hours and annual working weeks, where the Consumer Price Index is used to deflate earnings to 2010 dollars. All CPS calculations are weighted using the March supplement weights.

Compared to the median self-employed individual, the median salaried worker earns more per hour and has similar educational attainment. For example, salaried workers have on average 13.7 years of education, while the self-employed have 13.9. These summary statistics confirm the puzzle emerging from the extant literature: If entrepreneurship drives technological innovation and growth, it is odd that the self-employed, which are often used to draw inferences about entrepreneurship, earn less and have similar levels of education as salaried workers.

In contrast to past work, our demarcation between incorporated and unincorporated selfemployment highlights two differences. First, the median incorporated self-employed worker earns much more per hour-and works many more hours — than the median salaried and unincorporated individual. Indeed, median hourly earnings of the incorporated are about 80 percent greater than that of the unincorporated self-employed and 35 percent more than salaried employees. 
Second, the incorporated self-employed have distinct demographic and educational traits. The incorporated tend to be disproportionately white, male, and highly educated. For example, women account for 48 percent of the sample of workers, but only 28 percent of the incorporated self-employed. As another example, while 33 percent of salaried workers graduate from college, 46 percent of the incorporated self-employed have a college degree. Simply comparing salaried and self-employed workers conceals huge differences across employment types.

\section{B. NLSY79: Data and summary statistics on labor market outcomes and demographics}

The NLSY79 is a representative survey of 12,686 individuals who were 15-22 years old when they were first surveyed in 1979. ${ }^{2}$ Individuals were surveyed annually through 1994 and have since been surveyed biennially. We use survey years 1979 through 2012. Since nobody in our sample is above the age of 55, the NLSY79 sample corresponds to that of the CPS analyses. ${ }^{3}$ The NLSY79 survey is conducted every other year starting in 1994.

Although the NLSY79 surveys a smaller cross section of people than the CPS, it has two advantages. First, the NLSY79 is an extensive panel that traces individuals from when they were 15-22 years old through the age of 48-55. Thus, we follow virtually the entire career path of individuals. Second, the NLSY79 provides detailed information about the cognitive and noncognitive traits of individuals before they become prime age workers. Thus, we can examine how the traits of individuals when they were teenagers account for career choices later in life. We wait to describe these unique traits when we focus our examination on the sorting of individuals into different employment types based on these pre-labor market traits.

As shown in Table 1, the summary statistics from the NLSY79 and CPS provide very similar messages about labor market outcomes and basic demographics across employment types. ${ }^{4}$ First, the median earnings of salaried workers are greater than those of the self-employed. Second,

\footnotetext{
${ }^{2}$ We use the cross-sectional sample (6,111 individuals), the supplemental samples (5,295 individuals), and the military sample (1,280 individuals).

${ }^{3}$ Although Fairlie (2005) and Fairlie and Meyer (1996) document the similarities between CPS and NLSY samples, we note that the NLSY draws on a younger sample of individuals. Since the incorporated self-employed are older than other employment types, a smaller percentage of the NLSY sample is incorporated than the CPS sample.

${ }^{4}$ Since the basic unit of analysis is an individual-year observation and some people work in different employment types during their careers, we weight by the number of years the person worked in each type when providing summary statistics about fixed characteristics by employment type.
} 
this conceals enormous differences between the incorporated and unincorporated self-employed. The median incorporated self-employed individual earns about 50 percent more per hour and works about 25 percent more hours than the median salaried worker. In contrast, the median unincorporated business owner earns about 15 percent less per hour than the median salaried worker. Third, the incorporated self-employed are disproportionately white, male, and highly educated, while the unincorporated tend to be less educated than salaried workers. The incorporated are notably different from the unincorporated self-employed. Hurst, Li, and Pugsley (2014) show that the self-employed underreport their incomes, which might account for some of the lower median reported earnings of the unincorporated self-employed.

\section{Job task requirements—DOT: Data and summary statistics}

To assess whether the incorporated self-employed perform different tasks and run different types of businesses from the unincorporated, we use the U.S. Department of Labor's Dictionary of Occupational Titles (DOT) to measure the routine and nonroutine skills demanded of each occupation. The DOT was constructed in 1939 to help employment offices match job seekers with job openings. It provides information on the skills demanded of over 12,000 occupations. The DOT was updated in 1949, 1964, 1977, and 1991, and replaced by the O*NET in 1998. Given the timing of our study, we use the 1991 DOT, and confirm the results with the 1977 DOT.

The DOT aggregates information into five skill categories that are relevant for our study of entrepreneurship. For each category, it assigns a value between zero and ten, where higher values signify that the job requires more of that skill. The first two skill categories measure the nonroutine cognitive skills demanded by particular jobs.

- Nonroutine Analytical indicates the degree to which the task demands analytical flexibility, creativity, reasoning, and generalized problem-solving.

- Nonroutine Direction, Control, Planning indicates the degree to which the task demands complex interpersonal communications such as persuading, selling, and managing others.

We view these nonroutine cognitive skill categories as closely aligned with "entrepreneurial” activities, such as creating and commercializing a distinctive product, analyzing risks and market 
opportunities, coordinating the work of others, addressing an assortment of financial, organizational, and strategic challenges, and convincing others of the value of the endeavor.

The DOT also provides data on three categories of skills that align less directly with influential conceptions of entrepreneurship (e.g., Schumpeter (1911), Knight (1921), Baumol (1968, 1990), Lucas (1978), Murphy et al (1991), and Gennaioli et al. (2013).

- Nonroutine Manual measures the degree to which the task demands eye, hand, and foot coordination, which is high in such activities as landscaping, truck driving, carpentry, plumbing, and piloting an airline.

- Routine Analytical measures the degree to which the task requires the precise attainment of set standards, such as record-keeping or repetitive customer service (e.g., bank teller);

- Routine Manual measures the degree to which the task requires repetitive manual tasks, such as picking or sorting fruit or repetitive assembly.

To link the DOT measures to the CPS and NLSY79 data, we follow Autor, Levy, and Murnane (2003) and use the codes provided on David Autor's website. We use the DOT to examine cross-sectional differences in the skill requirements of the incorporated and unincorporated self-employed and to measure differences in the types of businesses run by incorporated and unincorporated business owners.

Table 2 provides summary statistics of the job task requirements across employment types. Panel A reports results for the CPS sample and Panel B reports summary statistics for the NLSY79 sample. In each panel, we present summary statistics on (1) the full sample of individuals and (2) the job task requirements of individuals last year if they were salaried workers last year. That is, we provide information on the job task requirements of their salaried jobs last year while differentiating by employment type this year.

Table 2 illustrates that (1) the incorporated self-employed engage in activities that demand greater nonroutine analytical skills than the unincorporated self-employed and salaried workers and (2) the unincorporated self-employed engage in jobs that demand greater manual skills than the incorporated self-employed and salaried workers. In both the CPS and NLSY79 samples, the incorporated self-employed have greater (a) Nonroutine Analytical and (b) Nonroutine Direction, 
Control, and Planning values than the unincorporated. In contrast, the unincorporated have larger Nonroutine Manual values. Aggregating the incorporated and unincorporated into a composite group of self-employed individuals blurs differences in the job task requirements of the activities associated with these distinct self-employment types.

The data in Table 2 also show that the sharp differences in the skills demanded of people who sort into incorporated and unincorporated self-employment exist before they become business owners. Individuals who become incorporated self-employed tend to have worked in salaried jobs demanding more nonroutine cognitive skills than those who become unincorporated business owners or those who remain as salaried employees. In contrast, people who become unincorporated self-employed tend to have worked in salaried jobs demanding a higher-level of manual skills. To the extent that one associates entrepreneurship with nonroutine cognitive activities, the summary statistics suggest that the incorporated self-employed engage (and engaged) in more quintessentially entrepreneurial activities than individuals opening unincorporated businesses.

\section{The Schumpeterian Entrepreneur and Other Self-employed Business Owners}

As stressed in the Introduction, we adopt a Schumpeterian conception of entrepreneurship in which entrepreneurs are creative economic leaders who disrupt existing market conditions and introduce new goods, services, and production processes. From this perspective, entrepreneurship is not primarily about efficiently coordinating the operation of a firm; it is primarily about breaking from the normal, identifying new opportunities, overturning existing structures, taking risk, and adding something novel to the market. ${ }^{5}$

Based on this view, we expect that entrepreneurs will engage in activities that demand comparatively high-levels of particular skills measured in the DOT. We expect that entrepreneurs will perform activities that demand disproportionately high-levels of Nonroutine Analytical and Nonroutine Direction, Control, and Planning skills, such as creative thinking, analytical flexibility, deft problem solving, and the ability to persuade others of the value of a new endeavor. In contrast,

${ }^{5}$ Bertrand and Schoar (2003), Bloom and Van Reenen (2007), and Malmendier and Tate (2009) examine the impact of middle- and upper-management on firm performance. Our focus is on the traits of entrepreneurs. 
the Schumpeterian conception of entrepreneurship does not stress other skills measured in the DOT, such as Nonroutine Manual and Routine Analytical skills. Of course, the link between the Schumpeterian concept of entrepreneurship and the measures of job skill requirements in the DOT is imperfect. But, Schumpeter's focus on creative destruction is more closely aligned with nonroutine cognitive skills than it is with sound eye-hand coordination.

Combining the Schumpeterian conception of entrepreneurship and the DOT's measures of job skill requirements provides testable implications about our empirical proxy of entrepreneurship: the incorporated self-employed. If entrepreneurs engage in activities that demand high-levels of nonroutine cognitive skills and if entrepreneurs favor the incorporated business form, then we should find that the incorporated self-employed perform activities that demand high-levels of expertise in creative thinking, analytical flexibility, adept problem solving, and the ability to motivate and persuade others. As noted in the Introduction, we expect entrepreneurs to favor the incorporated business form to the extent that limited liability and its separate legal identify facilitate novel, risky endeavors. In turn, we expect people opening more routine businesses that will benefit less from these legal characteristics to select the unincorporated business form given the additional reporting and organizational costs associated with incorporation. Based on this conceptual view of entrepreneurship, we now use the job task requirement data in the DOT to assess whether the incorporated self-employed perform different tasks and run different types of business from the unincorporated self-employed.

\section{A. Do the incorporated and unincorporated self-employed perform different activities?}

We use multinomial logit regressions to assess whether people who perform jobs that demand a high-level of Nonroutine Analytical, Nonroutine Direction, Control, and Planning (DCP), or Nonroutine Manual skills are more likely to become incorporated business owners. We examine the sorting into employment types based on the job task requirements of the individual as a salaried worker in year $t-1$ using the two-year matched panel of the CPS for work years 1995 through 2012, and further restrict the sample to individuals who were salaried workers in $t$-1.

Specifically we estimate a multinomial logit model assuming that the log-odds of each worker follow the following linear model: 


$$
\log \frac{P_{i j t}}{P_{i s t}}=\alpha_{j}+\sum_{k=1}^{3} \alpha_{j, N R, k} N R_{k, i t-1}+\alpha_{j, X} X_{i t-1} .
$$

The dependent variable is the log-odds ratio of being an incorporated (unincorporated) business owner rather than a salaried worker, where $P_{i j t}$ stands for the probability that person $i$ is incorporated $(j=1)$ or unincorporated self-employed $(j=2)$ in time $t$ and $P_{i s t}$ denotes the probability that the person is a salaried worker in time $t . N R_{k, i t-1}$ is a vector of $k=3$ nonroutine job specific skill requirements (Analytical, DCP, and Manual) of person's $i$ salaried job in year $t-1 . X_{i t-1}$ is a vector of regressors that includes demographics (race, gender), schooling, potential experience (quartic), the number of hours worked in year $t-1$, as well as state and year fixed effects. $\alpha_{j}$ is a constant and $\alpha_{N R, k, j}$ is a vector of regression coefficients for the incorporated and unincorporated.

The estimates reported in Table 3 provide four messages about the sorting of people into incorporated and unincorporated self-employment based on the job task requirements of their previous jobs. First, people who open incorporated businesses were more likely to have been working in salaried jobs that demand greater nonroutine cognitive abilities than people who remained in salaried jobs. Second, the opposite is true of the unincorporated: people who open unincorporated businesses were less likely to have been working in salaried jobs demanding strong Nonroutine Analytical abilities than people who remained in salaried jobs. Third, people who open incorporated businesses were less likely to have been working in salaried jobs that required a high degree of Nonroutine Manual skills than people who remained in salaried jobs. Fourth, the results on the unincorporated are different: people who start unincorporated businesses tend to have worked in jobs requiring greater Nonroutine Manual skills than those that remained salaried workers.

Table 3 offers additional information on who sorts into employment types. While individuals who worked more hours as salaried workers have a greater probability of becoming incorporated self-employed, the opposite is true for the unincorporated self-employed.

Furthermore, consistent with the summary statistics, the multinomial logit regressions indicate that women are less likely to become self-employed, especially incorporated self-employed, and more educated people are more likely to become incorporated self-employed. 


\section{B. Do the incorporated and unincorporated open different types of businesses?}

Turning from the individual to the firm, we now examine whether incorporated businesses are different from unincorporated ones. We use the skills demanded of a firm's employees to characterize the nature of the business. That is, we assume that the tasks performed by a firm's workers provide information about the business and assess whether the skills demanded of the workers in incorporated firms differ materially from those in unincorporated businesses.

To do this, we construct two measures of the job task requirements of each business. First, we compute the hours-weighted job task requirements of all workers in each industry over the work years 1995 through 2012 for each of three categories of skills: (1) Nonroutine Analytical skills, (2) Nonroutine Direction, Control, and Planning skills, and (3) Nonroutine Manual skills. In Table 4, we list the top- 5 and bottom- 5 industries of these three categories of the hours-weighted job task requirements of industries. The rankings seem intuitively plausible. As shown, taxicab service, trucking service, and logging are top-5 industries with respect to demanding high-levels of manual skills from their workers, but they are bottom-5 industries in terms of demanding nonroutine analytical skills from those same employees. In turn, engineering and architectural services demand high-levels of analytical skills from workers, while the legal services and accounting industries do not requirement much in the way of nonroutine manual skills from their workers. These industry-level data allow us to assess whether the incorporated self-employed are more likely to run businesses in industries that demand high levels of nonroutine cognitive skills than the unincorporated self-employed.

The second measure of the job task requirements of businesses further differentiates by firm size. Ideally, we would like to measure the job task requirements at the firm level since the average firm might differ from recently established businesses. To the extent that smaller firms in an industry serve as a better proxy for recently established businesses, the average by industry and firm size provides a more accurate measure of the job task requirements in new businesses. Specifically, the CPS places firms into different bins based on the number of employees. We compute the hours-weighted job task requirements of all workers in each firm-size bin in each industry over the work years 1995 through 2012. We do this for Nonroutine Analytical skills, 
Nonroutine Direction, Control, and Planning skills, and Nonroutine Manual skills. Thus, for each firm, we categorize its job task requirements based on its industry and size. With these industrysize-level data, we can evaluate whether the incorporated self-employed are more likely to run businesses — of the same size as owners of unincorporated firms — in industries that demand high levels of nonroutine cognitive skills.

Given these measures of the job task requirements of businesses, we assess whether people starting to run incorporated firms are more likely to do so in industries demanding stronger analytical skills than those starting to run unincorporated businesses. The sample includes individuals from the matched two-year CPS panel who were not self-employed in year $t$ - 1 but are self-employed in year $t$. The dependent variables in the odd numbered regressions of Table 5 are the hours-weighted values for Nonroutine Analytical, Nonroutine Direction, Control, and Planning, and Nonroutine Manual skills respectively demanded of workers in the industries run by the selfemployed business owner in year $t$. For the even number regressions, the dependent variables is the job task requirement of workers in the industry-size bin run by the self-employed business owner in year $t$. The regressor of interest is a dummy variable that equals one if the new business is incorporated and zero if the new business is unincorporated. In the odd number regressions, the incorporated dummy variable is the only regressor. The even numbered regressions include firm size, state, and year fixed effects, along with education (six categories) and experience (quartic).

The results in Table 5 show that incorporated and unincorporated businesses are very different. As shown in the odd numbered regressions, new incorporated businesses are (1) more concentrated in industries that demand stronger nonroutine cognitive skills from its workers and (2) less concentrated in industries that require stronger manual skills from workers than unincorporated businesses. The findings hold when differentiating businesses by industry and size. The results indicate that when an individual switches employment types to run an incorporated business, the business is more likely to be in an industry that demands a high degree of analytical skills from its workers than when an individual opens an unincorporated firm. In contrast, when an individual switches employment types to run an unincorporated business, it tends to be in an industry-firm size category that demands a comparatively high degree of manual skills. Mashing together the incorporated and unincorporated aggregates away striking differences these 
businesses. Taken together, the results reported in Tables 3, 4, and 5 suggest that the incorporated self-employed are more engaged in analytically demanding businesses, while the unincorporated self-employed are more engaged in providing manual services.

\section{Does incorporation reflect ex post sorting on business success?}

Using incorporation as an empirical proxy for “Schumpeterian entrepreneurship” requires that the legal form of the business reflects the entrepreneurial nature of the planned business activity and not simply (a) the ex post success of the business or (b) the expected success of the enterprise. With respect to ex post selection into incorporated self-employment based on the success of the business, the concern is that businesses start as unincorporated firms and then incorporate if they are successful. With respect to expected success, the concern is that individuals choose to establish incorporated businesses when they have a particularly promising business opportunity and become unincorporated business owners at other times. Under these conditions, incorporated self-employment might not reflect the entrepreneurial nature of the planned business activity. The evidence presented above indicates that incorporated businesses owners and their workers engage in activities demanding more nonroutine cognitive skills than those in unincorporated businesses, while unincorporated business owners and their workers tend to perform tasks demanding more manual skills. Nevertheless, we can also provide direct evidence on the degree to which individuals switch the legal form of their businesses and choose different legal forms for their different businesses throughout their careers.

To assess the concern that individuals incorporate when their unincorporated businesses are successful, we exploit the long-term panel nature of the NLSY79 and examine selfemployment spells. We define a self-employment spell as the full set of consecutive years in which a person is self-employed (either incorporated or unincorporated). For example, if a person is self-employed in 1991 and 1992, salaried in 1993, self-employed in 1994, and salaried in 1995, we define this person as having two self-employment spells. We examine all such spells in the NLSY79 sample, where some individuals experience more than one self-employment spell. If at the end of a self-employment spell the individual is an incorporated business owner, we determine how many years the individual was unincorporated self-employed before incorporating. Figure 1 
depicts these results for different groups of individuals: all, males, whites, and white-males. Similarly, if at the conclusion of a self-employment spell the individual is an unincorporated business owner, we determine how many years the individual was incorporated before becoming unincorporated self-employed. Figure 2 provides these results.

Figures 1 and 2 show that few people switch the legal forms of their businesses: people choose the legal form of the business when they choose to run it and rarely change afterwards. Figure 1 shows that in those cases when an individual ends a self-employment spell as an incorporated business owner, 85\% of the time the person also started the spell as an incorporated business owner. Most of the others switch in the first two years. Figure 2 indicates that $98 \%$ of those that end a self-employment spell as an unincorporated business owner also began the spell as unincorporated self-employed. The figures are consistent with the view that individuals select the legal form of their businesses ex ante, not based on the ex post success of the endeavor.

To evaluate the concern that individuals tend to select the incorporated business form when expected earnings from the business are especially high—regardless of the entrepreneurial nature of the business, we examine individuals with multiple self-employment spells. About half of the

people in our NLSY79 sample experience more than one self-employment spell. Of these, $84 \%$ are either incorporated or unincorporated in all of their spells. There is very little variation in the legal form of businesses across an individual's self-employment spells. This observation is both consistent with this Section's findings that the incorporated business owner engages in different types of activities and runs different types of businesses from the unincorporated and with the next Section's findings on the unique attributes of those who select into incorporated self-employed.

\section{Who Becomes an Entrepreneur? Evidence from the NLSY79}

Having established that the incorporated self-employed engage in activities and own firms that demand a comparatively high-level of nonroutine cognitive skills, we now focus on uncovering the cognitive and noncognitive traits associated with the self-sorting of individuals into different employment types. In particular, we use the unique attributes of the NLSY79 data to examine how the traits of individuals before they enter the prime age labor market account for subsequent career choices. Above, we focused on the skills demanded by particular jobs and 
industries. We now focus on the pre-labor market "supply” of cognitive and noncognitive traits. This section first provides definitions and summary statistics of the unique traits measured by the NLSY79. We then examine the self-sorting of individuals into incorporated and unincorporated self-employment based on these traits using multinomial logit regressions.

\section{A. Cognitive and Noncognitive Traits}

Besides the standard labor market statistics and demographics summarized in Table 1, the NLSY79 provides the following unique information on individual and family traits.

AFQT score (Armed Forces Qualifications Test score) measures the aptitude and trainability of each individual. Collected during the 1980 NLSY79 survey, the AFQT score is based on arithmetic reasoning, world knowledge, paragraph comprehension, and numerical operations. It is frequently employed as a general indicator of cognitive skills. This AFQT score is measured as a percentile of the NLSY79 survey, with a median value of 50 .

Rosenberg Self-Esteem score, which is based on a ten-part questionnaire given to all NLSY79 participants in 1980, measures the degree of approval or disapproval of one's self and has been widely used in psychology and economics (Bowles et al., 2001; Heckman et al., 2006). The values range from six to 30, where higher values signify greater self-approval.

Rotter Locus of Control measures the degree to which individuals believe they have internal control of their lives through self-determination relative to the degree that external factors, such as chance, fate, and luck, shape their lives. It was collected as part of a psychometric test in the 1979 NLSY79 survey. The Rotter Locus of Control ranges from four to 16, where higher values signify less internal control and more external control.

Illicit Activity Index measures the aggressive, risk taking, disruptive, "break-the-rules,” behavior of individuals based on the 1980 survey. We construct this index from 23 questions covering themes associated with skipping school, use of alcohol and marijuana, vandalism, shoplifting, drug dealing, robbery, assault, and gambling. For each question, we assign the value one if the person ever engaged in that activity and zero otherwise. To obtain the index, we simply add these values and divide by 23. Thus, the Illicit Activity Index ranges from 0 to 1, with higher values signifying more illicit behaviors. We also report results using the answers to some of the 
individual questions, such as whether the person ever used force to obtain things (Force), stole something of $\$ 50$ or less (Steal 50 or less), and whether the person was Stopped by the Police.

While some might view the Illicit Activity Index as only proxying (inversely) for risk aversion, our analyses caution against this presumption and hence highlight the degree to which the Illicit Activity Index measures the aggressive, disruptive activities of individuals as youths. After controlling for other traits, there is not a strong association between the Illicit Activity Index (measured in 1980) and the NLSY79's risk aversion indicator that assesses how much a person would sell an item with an expected, though risky, future value of \$5,000 (measured in 2006).

We use additional information on each individual's pre-labor market family traits, including data on parental education, whether the individual lived in a two-parent family at the age of 14, and family income in 1979, measured in 2010 dollars.

The NLSY79 also posed new questions in 2010 that provide helpful information in assessing the validity of using the unincorporated and incorporated self-employed as indicators of the ex ante nature of the business venture. To measure the degree to which an individual consider himself to be an entrepreneur, we use Entrepreneur, which equals one if the respondent in 2010 answers "yes" to the question, "Do you consider yourself to be an entrepreneur?” In posing the question, the NLSY79 defines an entrepreneur as "someone who launches a business enterprise, usually with considerable initiative and risk." To provide some information on the degree to which the individual is engaged in an innovative activity, we use Applied for Patent, which equals one if the respondent in 2010 answered, "yes" to the question, "Has anyone, including yourself, ever applied for a patent for work that you significantly contributed to?"

\section{B. Summary statistics on traits}

Individuals who become incorporated self-employed have distinct family backgrounds, as shown in Panel A of Table 6. The incorporated self-employed come from comparatively (1) highincome families as measured by family income in 1979, (2) well-educated families as measured by the education of the individual's parents, and (3) "stable” families as measured by whether the individual lived in a two parent family at the age of 14 . 
Moreover, individuals who become incorporated self-employed display striking cognitive and noncognitive characteristics before they enter the labor market (Table 6, Panel B). ${ }^{6}$ First, people who become incorporated self-employed had (1) higher “ability” as measured by AFQT values, (2) stronger self-esteem as measured by Rosenberg scores, and (3) stronger senses of controlling their futures, rather than having their futures determined by fate or luck, as measured by low Rotter Locus of Control scores. Second, people who spend more of their prime age working years as incorporated self-employed engaged in more illicit activities as youths. For example, the incorporated self-employed are twice as likely as salaried workers to report having taken something by force as youths; they are almost 40 percent more likely to have been stopped by the police; and, the incorporated self-employed have an overall illicit activity index (standardized for the full sample), which is measured when they were between the ages of 15 and 22, that is 21 percent greater than the index for salaried workers. Furthermore, while the unincorporated self-employed also tended to engage in more illicit activities as youths than salaried workers, the incorporated engaged in still more. ${ }^{7}$ All of these differences are statistically significant when using simple cross group t-tests.

In terms of these characteristics that are measured before people enter the prime age labor market, it is perhaps unsurprising that entrepreneurship is associated with stronger cognitive aptitude abilities and exceptional confidence in one's abilities, but it is perhaps more surprising entrepreneurs tend to engage in more illicit activities as youths than those who never become incorporated self-employed. As noted by Steve Wozniak, the co-founder of Apple, who hacked telephone systems early in his career, "... I think that misbehavior is very strongly correlated with and responsible for creative thought.”(Kushner, 2012) Our findings are also consistent with the work of Horvath and Zuckerman (1993), Zukerman (1994), and Nicolaou, Shane, Cherkas, and Spector (2008), who argue that personality traits influence sorting into entrepreneurship.

Furthermore, after working for a couple of decades, the incorporated self-employed are more likely to describe themselves as "entrepreneurs” and more likely to have contributed to a

\footnotetext{
${ }^{6}$ We report standardized values, so Rotter Locus of Control (standardized), Rosenberg Self-Esteem (standardized), and Illicit Activity Index (standardized) each has a mean of zero and a standard deviation of one.

${ }^{7}$ For the aggregate group of self-employed, Fairlie (2002) shows that people who engaged in drug dealing as youths are more likely to become self-employed later in life.
} 
patent. The variable Entrepreneur equals one if the individual responds "yes" to the question in the 2012 survey: "Do you consider yourself to be an entrepreneur (where an entrepreneur is defined by the questioner as someone who launches a business enterprise, usually with considerable initiative and risk)?" Since Entrepreneur is obtained decades after a person becomes prime age, we calculate the residuals from a regression of Entrepreneur on education, AFQT, Rosenberg SelfEsteem, Rotter Locus of Control, the Illicit Index, and year of birth. We then standardize these residuals to obtain Entrepreneur (residual standardized), which has a mean of zero and a standard deviation of one. We follow the same procedure to calculate Applied for Patent (residual standardized). As shown in Panel C of Table 6, Entrepreneur (residual standardized) equals 1.2 for the incorporated and 0.69 for the unincorporated. The difference is even larger when examining patents. Applied for Patent (residual standardized) is 0.28 for the unincorporated self-employed and only 0.03 for the unincorporated. The findings that the incorporated are more likely to classify themselves as entrepreneurs - and much more likely to have contributed to a patent — than other self-employed individuals are consistent with our strategy of using the incorporated as a better proxy for those engaged in entrepreneurial activities than the aggregate group of self-employed.

\section{Selection on cognitive and noncognitive traits}

To further assess the association between pre-labor market measures of cognitive and noncognitive traits and subsequent employment choices, we estimate a multinomial logit model assuming that the log-odds of each response follow the following linear model:

$$
\log \frac{P_{i j t}}{P_{i s t}}=\alpha_{j}+\alpha_{j, A} A F Q T_{i}+\alpha_{j, I} \text { Illicit }_{i}+\alpha_{j, A I} A F Q T_{i} \cdot \text { Illicit }_{i}+\alpha_{j, C N C} N C_{i}+\alpha_{j, X} X_{i} .
$$

The dependent variable is the log-odds ratio of being an incorporated (unincorporated) business owner rather than a salaried worker, where $P_{i j t}$ is the probability that person $i$ is incorporated $(j=1)$ or unincorporated self-employed $(j=2)$ in time $t$ and $P_{i S t}$ denotes the probability that the person is a salaried worker. We focus on cognitive ability ( $A F Q T)$ and noncognitive $(N C)$ traits: the Rotter locus of control indicator, the Rosenberg self-esteem measure, and Illicit. We also include an interaction between AFQT and Illicit. All specifications control for gender, race, and year-of-birth. In several specifications, we control for the education of the parents and family income (in 1979) 
to the estimate model. The vector $\left(X_{i}\right)$ in equation (2) represents these variables. By examining person-year observations, each person's “employment type” is defined by the number of years spent in each employment type. The errors are clustered at the individual level.

We report our findings in Table 7. In column (1), the Logit model assesses the probability of self-employment versus salaried; in columns (2) - (4), the comparison is between unincorporated self-employment and salaried; and in columns (5) - (6), the regression provides estimates of the impact of each trait on the probability that the person is incorporated relative to being a salaried worker.

Several findings emerge. First, the incorporated self-employed tend to be white, male, people with high self-esteem, individuals with a strong sense of controlling one’s future (i.e., a low Rotter locus of control score), individuals with high AFQT scores, those who engage in more illicit activities as youths, children of high-income parents, and people with well-educated mothers. The economic magnitudes in Table 7 are large. For example, holding other things constant, the odds of a woman becoming an incorporated business owner rather than a salaried employee are more than $70 \%$ less than for a similar male. As another example, the odds of becoming incorporated self-employed rather than a salaried employee for a person with an AFQT score in the $60^{\text {th }}$ percentile are $6.4 \%$ higher than for a person with the median AFQT score. ${ }^{8}$

Second, family income predicts of entrepreneurship. The coefficient estimates indicate that a $\$ 100,000$ increase in family income-which is enough to boost somebody from the $10^{\text {th }}$ to the $90^{\text {th }}$ percentile-is associated with a more than $50 \%$ increase in the odds of becoming incorporated self-employed relative to those of becoming a salaried employee, after controlling for the person's cognitive and noncognitive traits, and other characteristics of the person's family environment. To the extent that one views family income as a proxy for credit constraints after controlling for other factors, these results indicate that difficulties in obtaining finance materially influence incorporated self-employment but not unincorporated self-employment. ${ }^{9}$

Third, people who have both high AFQT scores and high Illicit Activity Index values are much more likely to become incorporated business owners. For example, compare two people

\footnotetext{
${ }^{8}$ AFQT was divided by 100 for the calculations in Table 7 , so $1.0637=\exp \{0.618 * 0.1\}$.

${ }^{9}$ For research on liquidity constraints and entrepreneurship, see, for example, the influential research by Blanchflower and Oswald (1998), Evans and Jovanovic (1989), and Holtz-Eakin, Joulfaian, and Rosen (1994).
} 
who are the same except for their AFQT and Illicit values. The first has the sample average value of Illicit (0) and the median value of AFQT (0.50), so that AFQT*Illicit equals zero. The second person, the "smart and illicit" person for this example, has one-quarter of one standard deviation above the mean value of Illicit (0.25) and is at the $75^{\text {th }}$ percentile of the AFQT distribution (0.75), so that AFQT*Illicit is about $0.1875(=0.25 * 0.75)$. Then the odds of the smart and illicit person becoming an incorporated self-employed business owners rather than a salaried employee are $6.3 \%$ greater (exp $\{0.327 * 0.1875)\}$ ) than the first person. The mixture of high learning aptitude and disruptive, “break-the-rules” behavior is tightly linked with entrepreneurship.

Fourth, Table 7 again emphasizes the differences in the pre-labor market characteristics of people who become incorporated and unincorporated self-employed business owners. While the unincorporated also tend to engage in more illicit activities as youths than salaried workers, they do not have higher AFQT scores or self-esteem values; and, they do not come from particularly high-income or well-educated families. Table 7 also shows that the combination of "smart" and “illicit” traits only boosts the probability of becoming incorporated self-employed.

\section{Selection on labor market productivity}

The NLSY79 data provide a unique opportunity to quantify the role of sorting on typically unobserved labor market skills. Almost all people_-about 90\% in our sample of full-time, fullyear working adults - are salaried workers at some point in their careers, so we observe almost all people in a common employment type. Thus, we can study the linkages between comparative success as a salaried worker and sorting into incorporated and unincorporated self-employment.

To do this, we proceed as follows. We compute each individual's adjusted hourly wages (Adjusted wages) as a full-time, full-year salaried employee by running run a wage regression that controls for experience as well as year and individual effects and use the estimated individual effects as Adjusted wages. We then run a new battery of multinomial logit regressions to assess whether productivity as a salaried worker_as measured by Adjusted wages_explains sorting into employment types and reports the results in Table 8. Moreover, and critically, we include the interaction between Adjusted wages and the Illicit Activity Index to assess whether the mixture of “productive” and illicit characteristics shapes employment decisions. The regressions also control 
for education and experience, as well as AFQT, the Rotter and Rosenberg Scores, Family income in 1979, and the education of each parent. To focus on a more homogeneous group of individuals, we only examine full-time, full year white males for the remainder of our analyses.

Table 8 reports two key results. First, although there is negative sorting into the aggregate category of self-employment on Adjusted wages, this reflects positive sorting into incorporated self-employment and negative sorting into unincorporated self-employment on Adjusted wages. We believe that this is the first paper to show that successful salaried workers are more likely to become entrepreneurs, while unsuccessful salaried workers are more likely to become unincorporated business owners. Second, comparatively successful salaried workers who were also heavily engaged in disruptive activities as youths have higher propensities to become incorporated business owners later in life. This is reflected in the positive, significant coefficient on the interaction term Adjusted wages*Illicit. Apparently, to the extent that Adjusted wages reflect productivity, it is a combination of comparatively high labor market productivity and a tendency to bend, if not break, the rules that influences who becomes an entrepreneur.

\section{E. Traits, employment types, and job task requirements}

We now examine the sorting into different types of business activities on both the legal form of the business and the underlying traits of the business owner. With the CPS data, we showed that incorporated and unincorporated business activities are different. Incorporated businesses tend to be in industries that demand a comparatively high degree of nonroutine cognitive skills from workers and a low degree of manual skills. But, unincorporated businesses tend to be in industries that demand a comparatively high degree of manual skills from their workers but a relatively low degree of nonroutine cognitive skills.

With the NLSY79, we can now match the cognitive and noncognitive traits of the individual business owner with the nature of his business. That is, we can examine the matching between the traits of individuals before they enter the labor market with the nature of the businesses, if any, that they later run. We measure the nature of the business by the job task requirements of the people employed by the business's industry. 
Table 9 provides regressions in which the dependent variable is a measure of the job task requirements of the industry in which each individual works. The reported explanatory variables are dummy variables of whether the individual is an incorporated or unincorporated business owner, where salaried employment is the excluded group. To measure the job task requirements of an industry, we again use the hours-weighted measure of the skills required of workers in each industry and we again examine three categories of skills: nonroutine analytical, nonroutine direction, control and planning, and nonroutine manual. The NLSY79 survey is conducted every other year starting in 1994. We further restrict the sample to individuals who were salaried in the last NLSY79 survey, i.e., in year $t$-2. Thus, we compare people who remain salaried with those who switch into incorporated or unincorporated self-employment. The regressions also control for individual and year fixed effects, and a quartic in experience. To work with a more homogeneous group, we restrict the sample to white males.

For each category of job task requirements, we examine four subsamples of individuals: (1) individuals with below (or equal to) the median values of either AFQT or Illicit (AFQT<=50 or Illicit<=0); (2) "smart and illicit" individuals with above the median values of both AFQT and Illicit (AFQT>50 and Illicit>0); (3) "very smart and illicit” individuals with above the $75^{\text {th }}$ percentile AFQT scores and an Illicit index value greater than the median (AFQT>75 and Illicit>0); and (4) "very smart but not illicit” individuals who have above the $75^{\text {th }}$ percentile AFQT scores but below (or equal to) the median values of the Illicit index (AFQT>75 and Illicit<=0).

We find that when "smart and illicit" individuals run incorporated businesses, they tend to be in industries that demand comparatively high-levels of creative thinking, analytically advanced problem solving, and communication skills from workers. This tendency is even stronger for the “very smart and illicit.” By comparing regressions (2) and (3) and (6) and (7), notice that the estimated coefficient on Incorporated is more than twice as large for the sample of individuals with AFQT $>75$ and Illicit $>0$ than for the sample of individuals with AFQT $>50$ and Illicit>0. Also, notice that the "very smart but not illicit” group of individuals who become incorporated business owners do not have a stronger tendency to open these types of businesses. The nature of the individual as a youth helps account for the type of incorporated business he runs later in life. 
Table 9 also provides insights on unincorporated businesses. When "smart and illicit" individuals become unincorporated business owners, the businesses are not disproportionately in industries demanding strong analytical skills from workers. Rather, when most types of people open unincorporated businesses, they tend to be in industries that demand strong manual skills. Even among people with smart and illicit traits as youths, those who run unincorporated businesses are not more likely to run analytically demanding businesses.

These analyses further advertise the value of disaggregating the self-employed into incorporated and unincorporated business owners. People with smart and illicit traits as youths are more likely to own incorporated businesses that demand highs levels of creative thinking, analytically advanced problem solving, and communication skills from their workers. In contrast, the unincorporated self-employed, even those with smart and illicit traits as teenagers, do not tend to run businesses with such demanding analytical skills. These findings are consistent with the view that the choice of the legal form of the business signals the nature of the planned business activity and suggest that when people start businesses engaged in more nonroutine activities—for which limited liability and the separate legal identity were created-they are more likely to select the incorporated business form.

\section{Entrepreneurs: Do They Earn More?}

In this section, we examine whether individuals earn more when they run incorporated businesses than when they work as salaried employees or as unincorporated business owners. Previous studies find that the typical self-employed business owner earns less than the typical salaried employee and conclude that entrepreneurship is associated with lower earnings.

In readdressing this question, we make two core contributions. First, we differentiate between incorporated business owners-who are closely aligned with the Schumpeterian conception of entrepreneurship_-and other self-employed individuals.

Second, we use panel data to address four challenges with determining whether individuals earn more as entrepreneurs. First, people might select into incorporated self-employment based on their earnings as salaried workers. If successful salaried workers are more likely to incorporate then the estimated earnings gap between salaried and incorporated individuals could reflect person 
effects and not the gains or losses associated with incorporated self-employment. Since the results above demonstrate that the typical incorporated business owner has very different cognitive and noncognitive traits from his salaried and unincorporated counterparts, person-specific influences are likely to represent a key challenge to assessing the comparative earnings of entrepreneurs. Second, people might start an unincorporated business and then incorporate if the business succeeds. The concern is that the higher earnings of the incorporated self-employed reflect selection on business success, rather than differences associated with the entrepreneurial nature of the business. Third, people might choose the incorporated business form when they expect high earnings — regardless of the entrepreneurial nature of the business — and the unincorporated legal form when the business seems less promising. The concern is that the estimated change in earnings associated with becoming an incorporated business owner might reflect this positive selection on expected earnings and not the change in earnings associated with entrepreneurship. Fourth, the estimated relationship between earnings and incorporated self-employment might reflect selective survivorship on ex-post success rather than a boost in earnings from entrepreneurship if unsuccessful incorporated business owners quickly select out of selfemployment and return to salaried work. We address each of these selection issues below.

We close this section on earnings by extending the analyses along two dimensions. First, we assess whether the same traits that account for who becomes an entrepreneur also explain comparative success as an entrepreneur. That is, are the same "smart and illicit" characteristics associated with selection into entrepreneurship also associated with larger increases in earnings when an individual becomes an incorporated business owner? As an external validity test, we also examine whether people with smart and illicit traits experience a larger increase in earnings when they become self-employed in industries that demand high levels of nonroutine cognitive skills from workers. Second, we examine the full distribution of earnings, not just the mean and median, and shed light on the risk to earnings associated with incorporated and unincorporated selfemployment. 


\section{A. Baseline earnings specification}

To frame the analyses, consider the following linear earnings equation:

$$
E_{i t}=\beta_{0}+\beta_{I} I_{i t}+\beta_{U} U_{i t}+\beta_{X} X_{i t}+\varepsilon_{i t},
$$

where $E_{i t}$ equals the earnings of individual $i$ in time $t$. To allow for nonpositive self-employment earnings, we examine earnings, not the log of earnings. $I_{i t}$ equals one if individual $i$ is incorporated self-employed in period $t$ and zero otherwise, and $U_{i t}$ is a similarly defined dummy variable for when individual $i$ is an unincorporated business owner. $\beta_{I}$ and $\beta_{U}$ are the gains in earnings associated with incorporated and unincorporated self-employment respectively relative to salaried earnings. $X_{i t}$ includes Mincerian characteristics (a quartic expression for potential work experience and dummy variables for six education categories) and year fixed effects. ${ }^{10} \varepsilon_{i t}$ is the error term that can be decomposed into time-invariant individual fixed effects $\left(\theta_{i}\right)$ and timevarying individual influences $\left(a_{i}(t)\right)$, along with a person-time shock to earnings $\left(\vartheta_{i t}\right)$ :

$$
\varepsilon_{i t}=\theta_{i}+a_{i}(t)+\vartheta_{i t} .
$$

When excluding such individual effects from the estimation, the estimated $\beta_{I}$ and $\beta_{U}$ parameters provide unbiased measures of the differences in residual earnings for individuals who run incorporated or unincorporated businesses respectively relative to salaried employees with similar Mincerian traits. When including individual effects in the estimation of equation (3), the estimates for $\beta_{I}$ and $\beta_{U}$ yield unbiased estimates of the differences in residual earnings for individuals who run incorporated and unincorporated businesses respectively relative to when they work as salaried employees.

Using data from the CPS and NLSY79, we examine annual and hourly earnings. We examine both annual and hourly earnings because the self-employed might have greater flexibility than salaried workers in choosing the number of work hours, as emphasized by Hurst and Pugsley (2011).

\footnotetext{
${ }^{10}$ Potential work experience (pwe) equals age minus years of schooling minus seven (or zero if this computation is negative). The quartic expression includes pwe, $\mathrm{pwe}^{2}$, $\mathrm{pwe}^{3}$, and $\mathrm{pwe}^{4}$, which are included in the annual and hourly wage regressions. The education categories are: (i) completed less than 9th grade, (ii) completed between 9th and 11th grade, (iii) graduated from high school, (iv) had some college education, (v) graduated from college, and (vi) obtained an advanced degree.
} 


\section{B. Evidence from the CPS}

Table 10 presents regression results on earnings based on the sample of white, prime age (25-55) males, who work full-time, full-year, while using the subsample of CPS observations for which we have a matched, two-year panel. The dependent variable is annual earnings in four of the eight regressions and hourly earnings in the other four. We provide OLS and median regressions. Using the matched, two-year panel allows us to conduct the CPS analyses both in levels and in first differences, which controls for individual fixed effects. ${ }^{11}$ With only a two-year panel, we cannot examine the potential impact of time-varying person-specific influences $\left(a_{i}(t)\right)$ on earnings. Below, we exploit the longer time-series dimension of the NLSY79 to address this and other limitations with the CPS

The results reported in Table 10 indicate that on average and at the median, the incorporated business owner earns more per hour and works more hours than his salaried and unincorporated full-time full-year counterparts, while the unincorporated business owner earns less. The coefficient estimates reported in regression (1) indicate that the mean residual earnings of the incorporated business owner are about \$32,402 more per annum than a salaried worker with the same observable characteristics. All values are in 2010 constant dollars. In contrast, the mean residual annual earnings of the unincorporated business owner are about $\$ 5,700$ less than those of a comparable salaried worker. Similar patterns emerge when examining hourly earnings, as shown in regression (5). On average, the residual hourly earnings of the incorporated self-employed are \$10.30 larger than those of a salaried worker with similar observable traits, while the estimated mean residual hourly earnings of the unincorporated self-employed are $\$ 4.10$ smaller than a comparable salaried employee. The median annual and hourly regressions (reported in columns (2) and (6) respectively) yield similar conclusions, though the estimated gaps in medians are smaller than the gaps in means.

To provide additional information on the sizes of these estimated differences in earnings, we compare the estimated dollar values of those differences to those of a comparator salaried worker and provide the percentage difference in the row labeled "\% Difference from Salaried

\footnotetext{
${ }^{11}$ The levels regressions (regression 1, 2, 5, and 6) can be run based on the full CPS sample. This yields coefficient estimates that statistically indistinguishable from those reported in Table 10.
} 
Worker. When we conduct the analyses using OLS, the comparator salaried worker is the average salaried worker in our sample of full-time, full year prime age white males. When conducting the analyses in medians, the comparator is the median salaried worker in our sample. Thus, the regression (1) estimates in Table 10 indicate that the mean residual annual earnings of the incorporated business owner are about $47.5 \%$ greater than those of the average salaried worker in our sample (i.e., $0.475=\$ 32,402 / \$ 68,158)$. In terms of hourly earnings, the estimates in regression (5) imply that that mean residual hourly earnings of the incorporated self-employed are $35.8 \%$ larger than the hourly earnings of the average salaried worker in the regression sample. Among full-time, full-year workers, the $11.7 \%$ percent difference between the annual and hourly earnings gains suggests that, on average, the incorporated self-employed work many more hours than salaried employees.

To account for individual effects, Table 10 presents regressions in first differences. In these regressions, the dependent variable is the change in annual earnings (regression 3 and 4 ) or the change in hourly earnings (regressions 7 and 8). They explanatory variables are differenced. Thus, $\Delta$ Incorporated equals the change in the incorporated self-employment status of the person between period $t$ and $t$-1. If somebody switches from salaried to incorporated self-employment, $\Delta$ Incorporated equals one; if somebody switches from incorporated self-employment to salaried work, it equals negative one; and if somebody does not switch his incorporated self-employment statues during the two-year period, then $\Delta$ Incorporated equals zero. $\Delta$ Unincorporated is similarly defined as the change in the unincorporated self-employment status. ${ }^{12}$

The first difference analyses indicate that individuals who become incorporated business owners tend to experience an increase in earnings relative to their own salaried earnings in the previous year. For example, the mean residual earnings of an individual who switches from a salaried job to become an incorporated self-employed business owner rise, on average, by \$7,906 per annum (regression 3) and \$2.70 per hour (regression 7). When comparing these estimated

\footnotetext{
${ }^{12}$ When we do not impose symmetry and allow the absolute value of the estimated change in earnings to differ when somebody switches from salaried work to incorporated self-employment from the estimated change when somebody switches from incorporated self-employment to salaried work, all of the reported results hold. Indeed, we find that when somebody returns to salaried work after incorporated self-employment, he returns to a wage rate that is very similar (in real terms) to the salary he had before becoming self-employed.
} 
dollar values to those of an average salaried work, we find that annual and hourly residual earnings rise by $11.6 \%$ and $9.4 \%$ respectively after accounting for time-invariant individual effects.

Our results also indicate that people who become incorporated business owners were earning much more as salaried workers than people with the same Mincerian traits who remained as salaried employees. To see this, compare the levels and first difference regressions. The first difference regressions account for individual effects, the levels regressions do not. Thus, the difference in these estimates provides information on the comparative earnings of people who become incorporated business owners when they were salaried workers and salaried workers with similar observable characteristics who do not become incorporated self-employed. The estimates in regressions (1) and (3) indicate that, on average, the person who incorporates in year $t$ enjoyed residual annual earnings of about $\$ 24,496(=\$ 32,402$ - $\$ 7,906)$ greater in year $t-1$ as a salaried worker than those of salaried workers in year $t-1$ with similar Mincerian traits who remain salaried. This difference is large. It implies that on average, the person who incorporates in year $t$ enjoyed residual earnings in $t-1$ that were $36 \%$ greater than those of the average salaried worker's annual earnings. Nevertheless, even after accounting for these individual effects, earnings tend to rise materially when a person becomes an incorporated business owner.

The results on the unincorporated are different, except when it comes to the change in the number of hours that individuals work. After controlling for individual effects and when comparing the estimated change in earning to the average and median salaried worker in the sample, regression (3) and (4) indicate that average and median residual earnings drop by $16.5 \%$ and $14.9 \%$ respectively when a person switches from a salaried job to unincorporated selfemployment; while average and median residual hourly earnings drop by about 17\% (columns 7 and 8). The contrast with the incorporated self-employed is stark: while the incorporated earn more per annum and per hour, the unincorporated earn less. However, both the incorporated and unincorporated work more hours than they did as salaried workers. To see this, note that the hourly earnings of those who switch from salaried work into unincorporated self-employment fall by more than their annual earnings, suggesting an increase in the number of hours worked. ${ }^{13}$

\footnotetext{
${ }^{13}$ In unreported examinations, we directly test and confirm that annual hours worked rises when individuals switch into either incorporated or unincorporated self-employment.
} 
These results on hours provide a new perspective on self-employment. Hurst and Pugsley (2011) stress the nonpecuniary benefits of being one's own boss. Our findings suggest that people exploit the flexibility of self-employment to work more hours, even among full-time full-year workers.

\section{Evidence from the NLSY79}

We now assess whether entrepreneurs earn more using data from the NLSY79. Although the NLSY79 includes a smaller cross-section of individuals than the CPS, we exploit the NLSY79's extensive panel to allow for time-varying person-specific influences $\left(a_{i}(t)\right)$ and address potential biases from selection into and out of employment types in estimating the expected gains relative to their earnings as salaried workers. In moving from the CPS to the NLSY79, we continue to use the same sample criteria (white males, who are full-time workers between the ages of 25 and 55). In addition to the $X_{i t}$ variables defined above, we also control for AFQT, Rosenberg self-esteem, Rotter Locus of Control, and the Illicit Activity Index in the NLS79 analyses. Since the NLSY79 survey is conducted every other year since 1994, the differencing is done between $t$ and $t-2$ for all years.

Table 11 confirms the four core messages emerging from the CPS regressions. First, on average and at the median, the incorporated business owner earns more per annum and per hour than his salaried and unincorporated counterparts. For example, consider the median analyses conducted in levels and without conditioning on individual fixed effects (columns 5 and 13). The coefficient estimates indicate that the median incorporated business owner's annual residual earnings are $\$ 23,941$ greater than those of the median salaried worker with the same observable characteristics and median residual hourly earnings are $\$ 5.32$ greater. These estimates are large, when compared to the median earnings of salaried workers. As shown in the row labeled "\% Difference from Salaried Worker," our estimates indicate that the median residual annual earnings of incorporated self-employed are $49 \%$ greater-and hourly earnings are $26 \%$ greater — than those of the median salaried worker. The corresponding OLS estimates (columns 1 and 9) are much greater. For example, the estimated annual residual earnings of the self-employed are $\$ 45,926$ larger than those of the average salaried worker. 
Second, after controlling for individual fixed effects, people who become incorporated business owners, on average and at the median, experience a material increase in annual and hourly earnings. For example, regressions (2) and (10) indicate that mean residual annual earnings of an individual increases by $29 \%$ when he becomes an incorporated business owner and his hourly earnings rise by $18 \%$, relative to the earnings of an average salaried worker. Thus, he earns more per hour, works more hours, and earns much more per annum after switching into incorporated self-employment. The results also hold when examining median earnings (columns 6 and 14), though the estimated relationships at the median are about one-third of the mean estimates, emphasizing the skewed distribution of incorporated self-employed earnings relative to salaried employment.

Third, there is positive selection into incorporated self-employment on salaried earnings. To see this, compare the OLS regression estimates in columns (1), which do not include individual fixed effects, with those in column (2), which condition on individual effects. The estimates suggest that on average, the person who runs an incorporated business earned $\$ 28,480$ more per annum as a salaried worker than a person with the same observable characteristics who did not become an incorporated business owner. This gap is large, as it equals $46 \%$ of the earnings of an average salaried worker in our sample. This is also reflected in median hourly earnings, where the estimated increase in median hourly earnings associated with incorporated self-employment is $5 \%$ when accounting for individual fixed effects and $26 \%$ when not conditioning out individual effects as shown in columns (13) and (14).

Fourth, the results on the unincorporated self-employed are distinct. The median residual hourly earnings of somebody who switches from salaried work to unincorporated self-employment tends to fall by $\$ 0.85$ (column 14 of Table 11) relative to his hourly earnings as a salaried worker. However, the individual tends to work more hours, so his median residual annual earnings do not fall significantly (column 6). Even though these analyses are limited to full-time, full-year workers, the self-employed work still more hours than they were working as salaried employees. Furthermore, there is evidence of negative selection into unincorporated self-employment on salaried earnings. For example, the estimated drop in median hourly earnings from unincorporated 
self-employment is much lower in absolute terms when accounting for individual fixed effects, as shown in columns (13) and (14). ${ }^{14}$

The NLSY79 allows us to control for, and assess the importance of, time-varying personspecific influences $\left(a_{i}(t)\right)$. The concern is that people might select into incorporated selfemployment based on trends in their earnings. If people with steeper earnings profiles have a greater propensity to become incorporated business owners, then some of the estimated increase in earnings associated with switching from salaried work to incorporated self-employment could reflect this trend rather than a change in earnings associated with entrepreneurship. Formally, we control for both an individual fixed effect and an individual-specific linear time trend.

The results hold, with only minor changes in the estimated parameters, when controlling for person-specific linear trends. This can be seen by comparing regression (3) and (4), (7) and (8), (11) and (12), and (15) and (16) in Table 11. When allowing for individual fixed effects and linear individual time-trends, we continue to find that the earnings of an individual tend to rise-relative to the individual's trend line-when he switches from salaried work to incorporated selfemployment as reported in columns (4), (8), (12), and (16). Again, the estimated effects are slightly smaller for hourly earnings, indicating that people tend to work more hours when they become self-employed, even among this sample of full-time, full-year workers. ${ }^{15}$

\footnotetext{
${ }^{14}$ As demonstrated below when we examine the full distribution of earnings, the positive selection into incorporated self-employment holds across virtually all percentiles, but selection into unincorporated is more nuanced.

${ }^{15}$ These results on earnings are robust to several additional tests. First, we were concerned that something odd could be happening during the year of incorporation. Thus, we omitted the two years before and the two years after incorporation and confirm the findings. Second, we were concerned that the results were driven by individuals buying into businesses in which they were working as salaried workers, rather than starting their own business. This is not the case. Virtually all of the switches into incorporation involve a change of firms. When we limit incorporation to situations in which a person changes firms, we get virtually identical results. Third, we were concerned that earnings growth might predict changes in employment type. Consequently, we examined the relationship between the change in hourly earnings between period $t-2$ and $t-4$ and the change in employment type from period $t$ to $t-2$. If the change in earnings is associated only with a contemporaneous change in employment type, then we expect this regression to yield an insignificant coefficient. If, however, increases in earnings tend to precede transitions into incorporated, then we would expect to find a positive coefficient. There is not a statistically significant relationship between a change in earnings and subsequent shifts into incorporated self-employment. While earlier results document the positive sorting into entrepreneurship on earnings, the evidence does not indicate that jumps in earnings are good predictors of subsequent shifts into incorporation; rather, earnings jump when people become incorporated business owners.
} 


\section{Selection into incorporated self-employment}

We next use self-employment spells to assess the degree to which the estimated positive relationship between entrepreneurship and earnings is influenced by positive selection into incorporated self-employment. The concern is that if many businesses start as unincorporated enterprises and then the successful ones incorporate-or if people select the incorporated business form when they expect relatively high earnings from the business, then the results presented above could reflect such positive selection on ex post or expected earnings and not an increase in earnings associated with entrepreneurship.

We already showed in Figures 1 and 2 that few people switch the legal form of their businesses within a self-employment spell, where a self-employment spell is the full set of consecutive years in which a person is self-employed. Figure 1 shows that $15 \%$ of selfemployment spells involve the individual switching from unincorporated to incorporated selfemployment. As noted, almost all of these switches occur within the first years of the spell. Figure 2 shows that almost no individuals switch from incorporated to unincorporated self-employment. Some of the switchers might be measurement error associated with people erroneously coding the legal form of their businesses in some years; but some might reflect selection on ex post success.

We now evaluate the degree to which these switchers within self-employment spells influence the estimated relationship between earnings and incorporated self-employment. To frame the issue we incorporate information on each individual's employment spells and rewrite the earnings equation (3) as follows:

$$
E_{i t s}=\beta_{0}+\beta_{I} I_{i t s}+\beta_{U} U_{i t s}+\beta_{X} X_{i t s}+\varepsilon_{i t s} .
$$

$E_{i t s}$ equals the earnings of individual $i$ in time $t$ in employment spell $s$. An employment spell is the full set of consecutive years as either a salaried or self-employed worker. Since we only consider full-time, full-year workers, individuals are either salaried or self-employed in each period. Thus, if somebody is always salaried, the person will experience just one employment spell. If a person is salaried for ten years, self-employed for one, and then salaried for 5 more years, the person experiences three employment spells. $I_{i t s}$ equals one if individual $i$ in spell $s$ during period $t$ is incorporated self-employed and zero otherwise. Thus, $I_{i t s}=0$ in all salaried employment spells. 
$U_{i t s}$ is a similarly defined dummy variable for when individual $i$, in period $t$, and spell $s$ is an unincorporated business owner. All of the variables and parameters in equation (5) are the same as those in equation (3). We simply acknowledge formally in equation (5) that some people change between incorporated and unincorporated self-employment during a single self-employment spell. The error term $\left(\varepsilon_{i t s}\right)$ can be decomposed into time-invariant and time-varying person-specific effects $\left(\theta_{i}\right.$ and $\theta_{t}(i)$ ), a person-spell specific shock to earnings $\left(\eta_{i s}\right)$ and a zero-mean person-time shock to earnings $\left(\vartheta_{i t s}\right)$ :

$$
\varepsilon_{i t s}=\theta_{i}+\theta_{t}(i)+\eta_{i s}+\vartheta_{i t s} .
$$

To address the concern that selection into incorporated self-employment based on success as an unincorporated business owner within a self-employment spell influences the estimated relationship between earnings and entrepreneurship, we eliminate within self-employment spell variation. We do this by defining a self-employment spell as incorporated or unincorporated based on the legal form of the business in the first year of the spell. In particular, we estimate the following earnings equation:

$$
E_{i t s}=\beta_{0}+\beta_{I} I_{i s}+\beta_{U} U_{i s}+\beta_{X} X_{i t s}+\varepsilon_{i t s},
$$

where $I_{i s}$ equals one for all years of individual $i$ 's self-employment spell $s$ if the individual started the spell as incorporated self-employed and zero otherwise. Note that $I_{i s}=1$ for all years of the self-employment spell $s$ when the individual starts the spell as incorporated self-employed regardless of whether he switches to unincorporated self-employment later in the spell. In Table 12, we refer to $I_{i s}$ as "Spell starts as incorporated." Similarly, $U_{i s}=1$ for all years of individual $i$ 's self-employment spell $s$ if the individual started the spell as an unincorporated self-employed business owner regardless of whether he switches to incorporated self-employment later in the spell. For individuals who do not switch from unincorporated to incorporated self-employment within an employment spell, $I_{i t s}=I_{i s}$ for all $t$ in the spell. However, for individuals who start a self-employment spell as an unincorporated business owner $\left(I_{i s}=0\right)$ and then incorporate later, then $I_{i t s}-I_{i s}=1$ for some periods within spell $s$. Thus, the results reported earlier based on equation (5) might reflect selection into incorporated self-employment from unincorporated selfemployment on the success of the business during spell $s\left(\eta_{i s}\right)$ rather than the gains from running 
an entrepreneurial business. To address this concern, Table 12, provides estimates based on equation (7).

The results are clear: Although Table 12 indicates positive selection into incorporated selfemployment on success as an unincorporated business owner, the earlier results hold. That is, there is a large increase in earnings when an individual becomes an incorporated self-employed business owner relative to his earnings as a salaried employee even after eliminating within selfemployment spell variation. For example, consider the OLS regressions on annual earnings. Regression (1) replicates the findings from Table 11 on Incorporated, which equals one in years when an individual is incorporated self-employed and zero otherwise. When controlling for individual fixed effects, the estimated increase in earnings from an individual switching from salaried work into incorporated self-employment is $\$ 17,446$. In regression (2), we do not examine Incorporated $\left(I_{i t s}\right)$. Rather, we examine Spell starts as incorporated $\left(I_{i s}\right)$. The estimated increase in earnings from an individual switching from salaried work into a self-employment spell in which the individual is incorporated self-employed in the first year is $\$ 14,064$. This suggests that some of the increase in earnings associated with becoming incorporated self-employed is that successful unincorporated business incorporate during the self-employment spell. But, the results further emphasize that even when eliminating this positive selection, there is still a material boost in annual income of $23 \%$ relative to the average salaried worker in the sample when somebody switches from salaried employment to run an incorporated business. It is also worth noticing that at the median, the point estimates are almost identical when we account for selection in (columns 5 and 6). This indicates there are only a few individuals who make it big as unincorporated business owners and then switch to incorporated self-employment.

Besides considering the potential influences of variation in the legal form of businesses within self-employment spells on the estimated change in earnings associated with incorporated self-employment, we were also concerned about variation across an individual's self-employment spells. As discussed above, half of individuals who become self-employed have two or more selfemployment spells. We were concerned that perhaps individuals choose to incorporate when they identify a particularly promising business opportunity and start unincorporated businesses when that is not the case. Under these conditions, the increase in earnings associated with incorporated 
self-employment might reflect this selection on expected success and not a boost in earnings associated with the entrepreneurial nature of the underlying business.

But, this concern does not materialize in the data. Specifically, we find that $84 \%$ of individuals with multiple self-employment spells choose to be either incorporated or unincorporated in all of their self-employment spells. There is very little variation in the legal form of businesses between an individual's self-employment spells. Moreover, when we categorize all of an individual's self-employment observations by the first year of his first self-employment spell and redo the analyses, all of the results hold. We include these analyses in Table 12. Specifically, we define the variable " 1 st year of 1st spell incorporated" as equal to one for each year of all of the years that an individual is self-employed if in the first year of his first employment spell the individual is incorporated self-employed and zero otherwise, and we set the variable " 1 st year of 1st spell unincorporated" equal to one for each year of all of the years that an individual is selfemployed if in the first year of his first employment spell the individual is unincorporated selfemployed and zero otherwise. We then use these definitions of incorporated and unincorporated re-estimate the earnings regressions. The results are provided in columns (4), (8), (12), and (16) of Table 12. We continue to find that an individual's earnings rise appreciably when he becomes incorporated self-employed-even after removing the potential effects of individuals choosing different legal forms for their businesses across self-employment spells. These findings are unsurprising given our early results that incorporated business owners engage in different types of activities and run different types of businesses from unincorporated business owners.

\section{E. Selection out of self-employment}

Another possible challenge to assessing whether entrepreneurs earn more is selection out of self-employment when the business is unsuccessful. Such "survivorship bias" would bias upwards the estimated relationship between earnings and self-employment by giving more weight (in the form of systemically more observations) to successful self-employment spells than unsuccessful ones. Using $I_{i s}$ and $U_{i s}$ in equation (7) addresses selection within self-employment but not selection out of self-employment. 
To evaluate the empirical importance of selection out of self-employment, we weight the observations in the earnings regressions by the inverse of the number of observations in each employment spell. An incorporated, unincorporated, or salaried employment spell includes the full set of consecutive observations of that employment type. Thus, if the person is incorporated for five consecutive observations, we weight each observation in that spell by one-fifth. If the person is salaried for six consecutive surveys, we weight each observation by one-sixth. In this way, we give equal weight to each employment spell. We report these results in regressions (3), (6), (9), and (12) of Table 12, where we continue to (a) include individual fixed effects and (b) use $I_{i s}$ and $U_{i s}$ to control for selection in.

We find that the self-employed exercise the option to dropout and return to salaried work when the business does not succeed, but the main findings hold after accounting for selection out. To see this compare the coefficient estimates between columns (3) and (4) for the OLS estimates and columns (7) and (8) for the median results. The point estimates are slightly lower and statistically indistinguishable. ${ }^{16}$

\section{F. Smart and illicit in entrepreneurial businesses}

We now use the earlier analyses on who becomes an entrepreneur to examine whether the same traits associated with selection into entrepreneurship are also associated with larger increases in earnings when an individual becomes an entrepreneur. To do this, we differentiate individuals by whether they are "smart and illicit" or not, using the same definitions that we used to examine the self-sorting of individuals into different employment types. In particular, we compare individuals with both high AFQT scores and strong tendencies to break the rules as youths (AFQT $>50$ and Illicit $>0$ ) to other individuals.

That is, we take the first difference of equation (7) and conduct the analyses while separately examining the samples of smart and illicit individuals and all others:

\footnotetext{
${ }^{16}$ The panel nature of the NLSY79 data also provides an opportunity to provide greater insights on the earnings profiles of individuals who try self-employment and then return to salaried work. First, we discover that individuals who experiment with entrepreneurship and then return to salaried employment on average return to higher paying salaried jobs (hourly earnings) than they had before becoming incorporated business owners. Second, the results on unincorporated self-employment are different. After an individual becomes an unincorporated self-employed business owner, his future hourly earnings fall regardless of whether he returns to salaried employment.
} 


$$
\Delta E_{i t s}=\delta_{0}+\delta_{1} \Delta I_{i s}+\delta_{2} \Delta U_{i s}+\delta_{3} \Delta X_{i t s}+u_{i t s} .
$$

The change in individual $i$ 's incorporated self-employment status is $\Delta I_{i s}$ and the change in individual $i$ 's unincorporated self-employment status is $\Delta U_{i s}$, where incorporated and unincorporated self-employment status are defined by the first year of the self-employment spell.

Table 13 provides estimates of the change in median residual annual and hourly earnings associated with switching into or out of incorporated and unincorporated self-employment. To control for positive selection into incorporated self-employment from unincorporated selfemployment, we continue to define a person's employment type by the first year of the employment spell. By conducting the earnings analyses in first differences and defining selfemployment type by the first year of the spell, the Table 13 analyses control for both selection in and out.

Table 13 indicates that "smart and illicit" individuals who become incorporated business owners enjoy much larger increases in annual and hourly earnings than (a) individuals who do not have these particular combinations of cognitive and noncognitive traits and become incorporated business owners and (b) smart and illicit individuals who become unincorporated business owners. That is, the same traits associated with selection into incorporated self-employment also account for the magnitude of the increase in earnings when an individual becomes an entrepreneur. For example, while the smart and illicit enjoy an almost $\$ 7,000$ increase in median residual annual earnings when they become incorporated business owners relative to their earnings as salaried workers (regression 2), others experience only a \$716 increase (regressions 1). The changes associated with the smart and illicit becoming incorporated self-employed are economically large. For example, the $\$ 7,000$ increase in median annual residual earnings associated with a smart and illicit individual becoming an incorporated business owner is $12 \%$ of the median residual earnings of their salaried smart and illicit counterparts. The smart and illicit experience much bigger increases in earnings when they become incorporated business owners, in absolute and relative terms, than people with different cognitive and noncognitive traits.

The results on the unincorporated self-employed are very different and emphasize (a) the sharp distinction between entrepreneurship and other self-employment activities and (b) the degree 
to which different combinations of traits are differentially valuable in different activities. In contrast to the findings on those who become incorporated business owners, Table 13 indicates that smart and illicit individuals who become unincorporated self-employed experience a larger drop in hourly earnings than individuals with different traits who become unincorporated business owners. The combination of smart and illicit traits is positively associated with success as an entrepreneur, but negatively associated with success in other self-employment activities.

There is, however, a concern that smart and illicit individuals are more likely than others to start incorporated businesses when they expect earnings to be especially high and not simply when they start an entrepreneurial business. To assess the robustness of our interpretation that the smart and illicit experience larger increases in income when they become entrepreneurs than individuals with other traits who open such businesses or than when the smart and illicit open noneentrepreneurial businesses, we assess whether the results hold without conditioning on the legal form of the business.

Using the same sample of people, we evaluate whether smart and illicit people experience especially large boosts in earnings when they become self-employed in "Schumpeterian industries," industries that demand high levels of nonroutine cognitive skills from workers. For simplicity, we divide industries by whether they are "Nonroutine cognitive industries” or not. Nonroutine cognitive industries are those that demand above average values of both (a) Nonroutine Analytical skills (analytical flexibility, creativity, reasoning, and generalized problem-solving) and (b) Nonroutine Direction, Control, Planning skills (complex interpersonal communications such as persuading, selling, and managing others) from its workers. Thus, "Nonroutine Cognitive Industry" equals one if the industry satisfies these criteria and zero otherwise As discussed above, we calculate the Nonroutine Analytical and Nonroutine Direction, Control, and Planning skills of an industry as the hours-weighted job task requirements of all workers in the industry over the work years 1995 through 2012 respectively in the CPS.

The focus on nonroutine cognitive industries reflects our earlier argument that nonroutine cognitive activities are closely aligned with the Schumpeterian conception of entrepreneurship, while industries that demand comparatively strong manual skills are less reflective of this conception. A key shortcoming with using this industry-level variation to assess gains in earnings 
associated with entrepreneurship is that the extra earnings from becoming self-employed in a nonroutine cognitive industry might reflect an industry effect rather than an "entrepreneurship” effect. By comparing smart and illicit individuals to others within and between industries our “differences-in-differences” external validity setting allows us to account for both the type of person and the type of industry effects on the change in earnings.

In regressions (3) and (4) of Table 13, the dependent variable remains the change in median annual earnings, but we no longer include $\Delta I_{i s}$ and $\Delta U_{i s}$ as regressors. Instead, we include: (1) $\Delta$ Self-Employed $x$ Nonroutine Cognitive Industry, which is the interaction between the change in the individual's self-employment status and whether the business is in a Nonroutine Cognitive Industry or not; (2) $\Delta$ Self-Employed, which is the change in the individual's selfemployment status; and (3) Nonroutine Cognitive Industry, which equals one if the person works, either as a salaried worker or as a self-employed business owner, in a Nonroutine Cognitive Industry. As with columns (1) and (2), columns (3) and (4) provide estimates for the sample of people who are not both smart and illicit and the sample of smart and illicit individuals respectively.

The results indicate that smart and illicit individuals who become self-employed business owners in Schumpeterian industries tend to experience large increases in annual earnings, but individuals without those traits actually tend to experience a drop in earnings when they become self-employed in nonroutine cognitive industries. That is, the same smart and illicit traits that are positively associated with (a) selection into incorporated self-employment, (b) selection into business ownership in nonroutine industries, and (c) increases in earnings when a person becomes an incorporated business owner are also positively associated with the increase in earnings associated with individuals becoming self-employed in industries that demand high levels of nonroutine cognitive skills from their workers. Indeed, as shown in regression (2), smart and illicit individuals earn more as self-employed only when they open businesses in nonroutine cognitive industry. The median gain in earnings from self-employment is approximately $\$ 6,613$ (\$8,163 $\$ 1,550)$, which is remarkably similar to those from incorporated self-employment. This cannot be attributed to a common industry self-employment effect (as the coefficient estimate on $\Delta$ SelfEmployed x Nonroutine Cognitive Industry in column 3 is actually negative). While selection into 
self-employment in routine and nonroutine industries is neither random nor exogenous to person characteristics, it is not contaminated by any ex ante or ex post selection into or out of incorporated self-employment vis-à-vis unincorporated self-employment. This robustness test provides additional evidence consistent with the view that a particular mixture of smart and illicit traits matters for success as an entrepreneur.

These findings on who succeeds as an entrepreneur contribute to existing research. Research indicates that self-esteem, optimism, and a taste for novelty are associated with a propensity for individuals to try self-employment (Horvath and Zuckerman 1993; Zukerman 1994; Nicolaou, Shane, Cherkas, and Spector 2008). ${ }^{17}$ Lazear $(2004,2005)$ stresses that entrepreneurs must be "jacks-of-all-trades" to coordinate factor inputs successfully. Our work demonstrates that a special mixture of cognitive and noncognitive skills - the combination of outstanding abilities and disruptive tendencies — is strongly associated with entrepreneurial success.

\section{H. Risk: The Distribution of Earnings and the Coefficient of Variation}

Previous work shows that the self-employed have a wider dispersion of earnings than salaried workers, suggesting that self-employment is much riskier than salaried employment (e.g., Hamilton 2000, and Moskowitz and Vissing-Jorgensen 2002). One explanation is that past work mixes together two very heterogeneous groups of self-employed-incorporated and unincorporated business owners - and the between group differences account for the wider dispersion of earnings among the self-employed. Another possible, not mutually exclusive, explanation is that the wider dispersion reflects the heterogeneity among the incorporated and unincorporated self-employed and not the gains and losses associated with self-employment. In this subsection, we first examine these possible explanations of the comparative dispersion of selfemployment earnings and then estimate the coefficient of variation of earnings in self-employment and salaried work to assess risk.

\footnotetext{
${ }^{17}$ Hartog, Praag, and Sluis (2010) do not find differences in the traits of the self-employed relative to salaried workers.
} 
Figures 3a and 3b report the quantile regression coefficient estimates from equation (7) for annual earnings for the incorporated and unincorporated respectively. ${ }^{18}$ We weight observations by the inverse number of observations in each employment spell. The blue bars provide the estimates without individual effects. Thus, for example, we compare the difference between residual earnings of the incorporated self-employed at the $90^{\text {th }}$ percentile of their earnings distribution with those of salaried workers at the $90^{\text {th }}$ percentile of their distribution in Figure 3a. As demonstrated by the findings in Tables 10 and 11, however, much of this gap, on average and at the median, reflects person specific factors. Thus, we also provide the quantile regression coefficient estimates when controlling for individual fixed effects in the red bars in Figures 3a and 3b. When conducting quantile analyses with individual fixed effects, we focus on individuals who change between salaried work and self-employment. In other words, after computing the gap between the residual earnings of a person when he is incorporated self-employed and those when he is salaried, the red bars in Figure 3a depict the quantiles of this gap.

Figures 3a and 3b show that both the incorporated and unincorporated self-employed have wider dispersions of earnings than the earnings distribution of salaried workers with comparable observable traits. To see this, consider the blue bars. Figure 3a indicates that exceptionally successful incorporated business owners $\left(90^{\text {th }}\right.$ percentile) tend to earn almost $\$ 95,000$ more per annum than exceptionally successful salaried workers. Furthermore, notice that the estimated gap in residual annual earnings is positive from the $20^{\text {th }}$ percentile onwards. Most people who run incorporated businesses earn more, and for much of the distribution much more, than comparable salaried workers. But, this is not true for the unincorporated; most people who run unincorporated businesses earn less, and some earn much less.

Figures 3a and 3b also show that individual effects account for much of the wider dispersion of the earnings for both the incorporated and unincorporated self-employed relative to salaried workers. For example, when we examine the gap in residual earnings of people when they are incorporated or salaried (red bars) at the different deciles of this gap, the dispersion is much flatter. For the incorporated self-employed (Figure 3a), the estimated gap is positive at each decile,

\footnotetext{
${ }^{18}$ When conducting the same exercise on hourly earnings, the figures are similar except that the absolute values of the estimates are smaller at each quantile. This reflects the earlier finding that people tend to work more hours when they are self-employed.
} 
indicating that earnings tend rise when individuals become incorporated self-employed across virtually the entire distribution. At the $90^{\text {th }}$ percentile of the gap, people tend to enjoy an almost $\$ 20,000$ increase in earnings when they become incorporated self-employed. For those who become unincorporated self-employed, the results are more nuanced. As discussed earlier, there is little change at the median. However, the estimated gap in residual earnings between a person's income as an unincorporated self-employed business owner and a salaried worker is negative for more than half of the distribution. At the upper end, however, the gap is large. At the $90^{\text {th }}$ percentile of the gap between unincorporated and salaried income, people tend to enjoy an almost $\$ 9,000$ increase in earnings when they become unincorporated self-employed. ${ }^{19}$

We further assess the relationship between risk and employment type by examining the coefficient of variation of earnings. For the NLSY79 sample, we compute the coefficient of variation over employment spells. For the matched, two-year CPS panel, we measure the coefficient of variation for observations in which the individual is in the same employment type for both years that we observe the individual. Thus, for these analyses, the CPS sample omits people who switch employment types during the two-year panel. In Table 14, we present regression results where the dependent variable is the coefficient of variation and the explanatory variables of interest are dummy variables for whether the person is incorporated or unincorporated self-employed, where salaried employment is the omitted category. For the NLSY79 regressions, we control for the number years in the employment spell, along with experience and year effects. ${ }^{20}$

Table 14 indicates that the coefficient of variation in earnings is greater when a person is an incorporated business owner than when the person is a salaried worker. Consider the NLSY79 results, which are very similar to those from the CPS. The estimated coefficient of variation for the average salaried worker is 0.30 , as indicated by the estimated constant, while the estimated coefficient of variation for incorporated business owners is $0.48(=0.30+0.18)$. As noted above,

\footnotetext{
${ }^{19}$ Figures 3a and 3b also provide additional evidence on selection into self-employment on earnings as a salaried worker, building on the OLS and median estimates in Tables 10 and 11. Figure 3a demonstrates that there is positive selection into incorporated self-employment from at least the $20^{\text {th }}$ percentile upward. The results for the unincorporated are again more nuanced as shown in Figure 3b. While there is small, negative selection at the median, this selection becomes much more negative at lower quantiles, indicating that many of the unsuccessful unincorporated self-employed were unsuccessful salaried workers. However, there is positive selection into unincorporated self-employment from the $60^{\text {th }}$ percentile upward.

${ }^{20}$ In unreported regressions, we control for experience and education (as well as cognitive and noncognitive traits in the NSLY79 sample) and obtain virtually the same coefficient estimates and standard errors as those in Table 14.
} 
the estimated increase in annual earnings for an individual show chooses to become an incorporated business owner is $12 \%$. For comparison purposes, the coefficient of variation for the S\&P500 over 1926-2002 period is about 1.8 and the average annual return is about $12 \% .{ }^{21}$ Taken together, the results provided in Table 14 and Figures 3a and 3b are consistent with the Schumpeterian conception that entrepreneurs undertake risky endeavors that offer the possibility of enormous boosts in earnings.

\section{Conclusions}

We disaggregate the self-employed into the incorporated and unincorporated to distinguish between "entrepreneurs" and other business owners. We show that incorporated business owners tend to engage in jobs that demand stronger nonroutine cognitive skills than either unincorporated business owners or salaried workers. In contrast, unincorporated business owners tend to perform tasks that demand manual skills. To the extent that one associates entrepreneurship with analytical reasoning, creativity, and complex interpersonal communications rather than with eye, hand, and foot coordination, the data suggest that on average the incorporated self-employed engage in entrepreneurial activities while the unincorporated do not. Thus, there are material problems with using the aggregate group of self-employed as an empirical proxy of entrepreneurship.

We discover that entrepreneurs — as proxied by the incorporated self-employed — earn more and have a very distinct mixture of cognitive and non-cognitive traits than salaried workers and other business owners. The incorporated tend to be male, white, better-educated, and more likely to come from high-earning, two-parent families. Furthermore, as teenagers, the incorporated tend to have higher learning aptitude and self-esteem scores. But, apparently it takes more to be a successful entrepreneur than having these strong labor market skills: the incorporated selfemployed also tend to engage in more illicit activities as youths than other people who succeed as

\footnotetext{
${ }^{21}$ Over the period from 1926-2002, Ibbotson EnCorr Analyzer indicates that the coefficient of variation (CV) on the S\&P 500 is 1.78, with a standard deviation of $21.9 \%$ and an arithmetic mean return of $12.3 \%$. Over the same period, the CV on 30-day T-bills is 0.237 , with a standard deviation of $0.9 \%$ and mean of $3.8 \%$, and the CV for long-term government bonds is 1.414 , with standard deviation of $8.2 \%$ and mean returns of $5.8 \%$.
} 
salaried workers. It is a particular mixture of traits that seems to matter for both becoming an entrepreneur and succeeding as an entrepreneur. It is the high-ability person who tends to "breakthe-rules” as a youth who is especially likely to become a successful entrepreneur. 


\section{References}

Autor, David H., Frank Levy, and Richard J. Murnane. 2003. The skill content of recent Technological change: An empirical investigation. Quarterly Journal of Economics 118 (4): 1279-1333.

Baumol, William J. 1968. Entrepreneurship in economic theory. American Economic Review 58(2): 64-71.

Baumol, William J. 1990. Entrepreneurship: Productive, unproductive, and destructive. Journal of Political Economy 98(5): 893-921.

Bernardo, Antonio E., and Ivo Welch. 2001. On the evolution of overconfidence and entrepreneurs. Journal of Economics \& Management Strategy 10 (3): 301-330.

Bertrand, Marianne, and Antoinette Schoar. 2003. Managing with style: the effect of managers on firm policies. Quarterly Journal of Economics 118(4): 1169-1208.

Blanchflower, David G., and Andrew J. Oswald. 1998. What makes and entrepreneur? Journal of Labor Economics 16 (1): 26-60.

Bloom, Nicholas, and John Van Reenen. 2007. Measuring and explaining management practices across firms and countries. Quarterly Journal of Economics 122(4): 1351-1408.

Borjas, George J., Stephen G. Bronars. 1989. Consumer discrimination and self-employment. Journal of Political Economy 97 (June): 581-605.

Bowles, Samuel, Herbert Gintis, and Melissa Osborne. 2001. The determinants of earnings: A behavioral approach. Journal of Economic Literature 39 (4): 1137-1176.

Dawson, Christopher, David de Meza, Andrew Henley, and G. Reza Arabsheibani. 2011. Entrepreneurship, cause or consequence of financial optimism. LSE mimeo.

De Meza, David, and C. Southey. 1996. The borrower’s curse: Optimism, finance, and entrepreneurship. Economic Journal 106: 375-386.

Evans, David S., and Boyan Jovanovic. 1989. An estimated model of entrepreneurial choice under liquidity constraints. Journal of Political Economy 97 (4): 808-27.

Evans, David S., and Linda S. Leighton. 1989. Some empirical aspects of entrepreneurship. American Economic Review 79 (June): 519-35.

Fairlie, Robert W. 2002. Drug dealing and legitimate self-employment. Journal of Labor Economics 20(3): 538-567.

Fairlie, Robert W. 2005. Self-employment, entrepreneurship, and the NLSY79. Monthly Labor Review 128 (February): 40-47.

Fairlie, Robert W., and Bruce D. Meyer. 1996. Ethnic and racial self-employment differences and possible explanations. Journal of Human Resources 31 (Autumn): 757-793.

Garicano, Luis, and Esteban Rossi-Hansberg. 2006. Organization and inequality in a knowledge economy. Quarterly Journal of Economics (November): 1383-1435. 
Glaeser, Edward L. 2007. Entrepreneurship and the city. NBER Working Paper 13551.

Gennaioli, Nicola, Rafael La Porta, Florencio Lopez-de-Silanes, and Andrei Shleifer. 2013. Human capital and regional development. Quarterly Journal of Economics 128: 105-164.

Hamilton, Barton H. 2000. Does entrepreneurship pay? An empirical analysis of the returns to self-employment. Journal of Political Economy 108 (3): 604-631.

Harris, Ron. 2000. Industrializing English Law: Entrepreneurship and Business Organization, 1720-1844. New York: Cambridge University Press.

Hartog, Joop, Mirjam van Praag, and Justin van der Sluis. 2010. If you are so smart, why aren’t you an entrepreneur? Returns to cognitive and social ability: Entrepreneurs versus employees. Journal of Economics and Management Strategy 19(4): 947-989

Heckman, James J., 2000. Policies to foster human capital. Research in Economics, Elsevier, vol. 54(1): 3-56.

Heckman, James J., and Yona Rubinstein. The importance of noncognitive skills: Lessons from the GED testing program. American Economic Review 91(May): 145-149.

Heckman, James J., N. Stixrud, and S. Urzua. 2006. The effects of cognitive and noncognitive abilities on labor market outcomes and social behavior. Journal of Labor Economics 24 (3): 411-482.

Hipple, Steven F. 2010. Self-employment in the United States. Monthly Labor Review 113 (November): 17-32.

Holmes, Thomas J., and James A. Schmitz, Jr. 1990. A theory of entrepreneurship and its application to the study of business transfers. Journal of Political Economy 98 (April): 265-94.

Holtz-Eakin, Douglas, David Joulfaian, and Harvey S. Rosen. 1994. Sticking it out: Entrepreneurial survival and liquidity constraints. Journal of Political Economy 102 (February): 53-75.

Horvath, Paula, and Marvin Zuckerman. 1993. Sensation seeking, risk appraisal, and risky behavior. Personality and Individual Differences 14 (January): 41-52.

Hurst, Erik, Geng Li, and Benjamin W. Pugsley. 2014. Are household surveys like tax forms: Evidence from income underreporting of the self-employed. Review of Economics and Statistics 96 (March): 19-33.

Hurst, Erik, and Benjamin W. Pugsley. 2011. What do small businesses do? Brookings Papers on Economic Activity (Fall 2011): 73-118.

Kihlstrom, Richard, and Jean-Jaques Laffont. 1979. A general equilibrium entrepreneurial theory of firm formation based on risk aversion. Journal of Political Economy 87 (August): 71948.

Knight, Frank H. 1921. Risk, Uncertainty and Profit. New York: Harper and Row. 
Kushner, David. 2012. Machine Politics: The Man Who Started the Hacker Wars. The New Yorker, May 7.

La Porta, Rafael and Andrei Shleifer. 2008. The unofficial economy and economic development. Brookings Papers on Economic Activity, 275-352.

Lazear, Edward P. 2004. Balanced skills and entrepreneurship. American Economic Review, 94(2): 208-211.

Lazear, Edward P. 2005. Entrepreneurship. Journal of Labor Economics 23 (4): 649-680.

Lerner, Josh, Ann Leamon, and Felda Hardymon. 2012. Venture Capital, Private Equity, and the Financing of Entrepreneurship. New York: Wiley.

Lucas, Robert E. 1978. On the size distribution of business firms. The Bell Journal of Economics 9(2): 508-523.

Madrian, Bridgette C., and Lars John Lefgren. 2000. An approach to longitudinally matching Current Population Survey (CPS) respondents. Journal of Economic and Social Measurement 26(1): 31-62.

Malmendier, Ulrike, and Geoffrey Tate. 2009. Superstar CEOs. Quarterly Journal of Economics 124(4): 1593-1638.

Manso, Gustavo. 2015. Experimentation and the returns to entrepreneurship. University of California, Berkeley, mimeo.

Moskowitz, Tobias, and Annette Vissing-Jorgensen. 2002. The returns to entrepreneurial investment: A private equity premium puzzle? American Economic Review 92 (4): 745778.

Mulligan Casey, B. and Yona Rubinstein. 2008. Selection, investment, and women's relative wages. Quarterly Journal of Economics 123(3): 1061-1110.

Murphy, Kevin M., Andrei Shleifer, and Robert W. Vishny. 1991. The allocation of talent: Implications for growth. Quarterly Journal of Economics 106(2): 503-530.

Nicolaou, Nicos, Scott Shane, Lynn Cherkas, and Tim D. Spector. 2008. The influence of sensation seeking in the heritability of entrepreneurship. Strategic Entrepreneurship Journal 2 (March): 7-21.

Schumpeter, Joseph A. 1911. Theorie Der Wirtschaftlichen Entwicklung. Leipzig: Duncker \& Humblot.

Shleifer, Andrei and Robert W. Vishny. 1997. A survey of corporate governance. Journal of Finance 52(2): 737-83.

Smith, Adam. 1776. An Inquiry into the Nature and Causes of the Wealth of Nations. London: Methuen and Co.

Zuckerman, Marvin 1994. Behavioral Expressions and Biosocial Bases of Sensation Seeking. New York: Cambridge University Press. 
Table 1: Demographics and Labor Market Outcomes by Employment Type, CPS and NLSY79

\begin{tabular}{|c|c|c|c|c|c|}
\hline & \multirow[t]{2}{*}{ All } & \multirow[t]{2}{*}{ Salaried } & \multicolumn{3}{|c|}{ Self-Employed } \\
\hline & & & All & Uninc. & Inc. \\
\hline \multicolumn{6}{|c|}{ Panel A: CPS 1996 - 2012} \\
\hline \multirow[t]{2}{*}{ Observations } & $1,225,886$ & $1,108,591$ & 117,295 & 75,476 & 41,819 \\
\hline & $100.0 \%$ & $90.4 \%$ & $9.6 \%$ & $6.2 \%$ & $3.4 \%$ \\
\hline \multicolumn{6}{|l|}{ A. Labor Market Outomes } \\
\hline Mean Earnings & $\$ 47,515$ & $\$ 46,421$ & $\$ 58,174$ & $\$ 40,820$ & $\$ 89,169$ \\
\hline Median Earnings & $\$ 36,090$ & $\$ 36,363$ & $\$ 34,190$ & $\$ 24,625$ & $\$ 55,591$ \\
\hline Median Hourly Earnings & $\$ 18.0$ & $\$ 18.0$ & $\$ 17.4$ & $\$ 13.8$ & $\$ 24.6$ \\
\hline Annual Hours Worked & 1985 & 1976 & 2078 & 1936 & 2331 \\
\hline Full-Time, Full-Year & 0.69 & 0.70 & 0.64 & 0.57 & 0.78 \\
\hline \multicolumn{6}{|l|}{ B. Demographics } \\
\hline Age & 40.2 & 40.0 & 42.9 & 42.4 & 43.6 \\
\hline White & 0.70 & 0.69 & 0.79 & 0.76 & 0.83 \\
\hline Female & 0.48 & 0.49 & 0.36 & 0.40 & 0.28 \\
\hline Years of Schooling & 13.7 & 13.7 & 13.9 & 13.6 & 14.5 \\
\hline College Graduate (or more) & 0.33 & 0.33 & 0.36 & 0.31 & 0.46 \\
\hline \multicolumn{6}{|c|}{ Panel B: NLSY79 1982-2012 } \\
\hline \multirow[t]{2}{*}{ Observations } & 132,681 & 121,782 & 10,899 & 8,963 & 1,936 \\
\hline & $100.0 \%$ & $91.8 \%$ & $8.2 \%$ & $6.8 \%$ & $1.5 \%$ \\
\hline \multicolumn{6}{|l|}{ A. Labor Market Outomes } \\
\hline Mean Earnings & & $\$ 43,605$ & $\$ 55,785$ & $\$ 45,713$ & $\$ 93,411$ \\
\hline Median Earnings & $\$ 35,170$ & $\$ 35,222$ & $\$ 33,965$ & $\$ 28,672$ & $\$ 61,424$ \\
\hline Median Hourly Earnings & $\$ 17.2$ & $\$ 17.2$ & $\$ 16.8$ & $\$ 14.7$ & $\$ 26.2$ \\
\hline Annual Hours Worked & 1966 & 1953 & 2088 & 1991 & 2461 \\
\hline Full-Time, Full-Year & 0.59 & 0.59 & 0.53 & 0.48 & 0.72 \\
\hline \multicolumn{6}{|l|}{ B. Demographics } \\
\hline Age & 36.2 & 36.0 & 38.1 & 37.5 & 40.1 \\
\hline White & 0.81 & 0.80 & 0.87 & 0.86 & 0.90 \\
\hline Female & 0.47 & 0.48 & 0.38 & 0.41 & 0.28 \\
\hline Years of Schooling & 13.8 & 13.8 & 13.6 & 13.4 & 14.2 \\
\hline College Graduate (or more) & 0.30 & 0.30 & 0.26 & 0.23 & 0.36 \\
\hline \multicolumn{6}{|c|}{$\begin{array}{l}\text { Notes: The table presents summary statistics from the March Annual Demographic Survey files of the } \\
\text { Census Bureau's CPS for the work years } 1995 \text { through 2012, for prime age workers ( } 25 \text { through } 55 \text { years } \\
\text { old), and from the Bureau Labor of Statistics' National Longitudinal Survey of Youth } 1979 \text { (NLSY79) for } \\
\text { workers who are least } 25 \text { years old between } 1982 \text { and } 2012 \text {. The CPS and the NLSY79 classify all workers } \\
\text { in each year as either salaried or self-employed, and among the self-employed, they indicate whether } \\
\text { the person is incorporated or unincorporated self-employed. The sample excludes people who do not } \\
\text { work either as salaried or self-employed, people with missing data on relevant demographics and labor } \\
\text { market outcomes, and people living within group quarters. }\end{array}$} \\
\hline
\end{tabular}




\begin{tabular}{|c|c|c|c|c|c|}
\hline & \multirow[t]{2}{*}{ All } & \multirow[t]{2}{*}{ Salaried } & \multicolumn{3}{|c|}{ Self-Employed } \\
\hline & & & All & Uninc. & Inc. \\
\hline \multicolumn{6}{|c|}{ Panel A: CPS 1996 - 2012} \\
\hline \multicolumn{6}{|l|}{ 1. Job Task Requirements } \\
\hline Nonroutine Analytical & 3.91 & 3.87 & 4.27 & 3.93 & 4.89 \\
\hline Nonroutine Direction, Control, Planning & 3.00 & 2.92 & 3.87 & 3.19 & 5.10 \\
\hline Nonroutine Manual & 0.99 & 0.99 & 0.98 & 1.08 & 0.80 \\
\hline \multicolumn{6}{|c|}{ 2. Job Task Requirements Last Year (if salaried) } \\
\hline Nonroutine Analytical & 4.04 & 4.01 & 4.15 & 3.79 & 4.66 \\
\hline Nonroutine Direction, Control, Planning & 3.15 & 3.11 & 3.46 & 2.79 & 4.41 \\
\hline Nonroutine Manual & 0.95 & 0.96 & 0.97 & 1.10 & 0.78 \\
\hline \multicolumn{6}{|c|}{ Panel B: NLSY79 1982-2012 } \\
\hline \multicolumn{6}{|l|}{ 1. Job Task Requirements } \\
\hline Nonroutine Analytical & 3.72 & 3.73 & 3.65 & 3.43 & 4.51 \\
\hline Nonroutine Direction, Control, Planning & 2.73 & 2.69 & 3.12 & 2.80 & 4.33 \\
\hline Nonroutine Manual & 1.05 & 1.03 & 1.19 & 1.25 & 0.95 \\
\hline \multicolumn{6}{|c|}{ 2. Job Task Requirements Last Year (if salaried) } \\
\hline Nonroutine Analytical & 3.72 & 3.73 & 3.69 & 3.53 & 4.30 \\
\hline Nonroutine Direction, Control, Planning & 2.67 & 2.67 & 2.69 & 2.41 & 3.70 \\
\hline Nonroutine Manual & 1.05 & 1.03 & 1.17 & 1.23 & 0.97 \\
\hline \multicolumn{6}{|c|}{$\begin{array}{l}\text { Notes: The table presents summary statistics from the March Annual Demographic Survey files of the Census } \\
\text { Bureau's CPS for the work years } 1995 \text { through 2012, for prime age workers ( } 25 \text { through } 55 \text { years old), and } \\
\text { from the Bureau Labor of Statistics' National Longitudinal Survey of Youth } 1979 \text { (NLSY79) for workers who are } \\
\text { least } 25 \text { years old between } 1982 \text { and 2012. For Panels A and B, we use data on job task requirements from } \\
\text { Autor, Levy, and Murnane (2003), who link data from the Dictionary of Occupational Titles with the } \\
\text { occupational categories in the CPS. Nonroutine Analytical measures the degree to which the task demands } \\
\text { analytical flexibility, creativity, and generalized problem-solving, including tasks such as forming and testing } \\
\text { hypotheses, making medical diagnoses, etc. Nonroutine Direction, Control, Planning measures the degree to } \\
\text { which the task demands complex interpersonal communications such as persuading, selling, and managing } \\
\text { others. Nonroutine Manual measures the degree to which the task demands eye, hand, and foot coordination, } \\
\text { including landscaping, truck driving, carpentry, plumbing, and piloting a commercial airline. For Panel A.2 we } \\
\text { only include individuals who (a) are part of the matched CPS sample, in which we create a two-year panel for } \\
\text { the subset of individuals that we match overtime following the guidelines in Madrian and Lefren (2000) and } \\
\text { (b) were salaried workers in year t-1. }\end{array}$} \\
\hline
\end{tabular}


Table 3: Selection into Unincorporated and Incorporated Self-Employment, CPS Panel

\begin{tabular}{|c|c|c|}
\hline & \multirow{2}{*}{$\begin{array}{c}\text { Unincorporated } \\
(1)\end{array}$} & \multirow{2}{*}{$\frac{\text { Incorporated }}{(2)}$} \\
\hline & & \\
\hline \multicolumn{3}{|l|}{ Job Task Requirements Last Year: } \\
\hline Nonroutine Analytical & $\begin{array}{c}-0.038 * * \\
(0.019)\end{array}$ & $\begin{array}{c}0.055^{* * *} \\
(0.017)\end{array}$ \\
\hline Nonroutine Direction, Control, Planning & $\begin{array}{l}-0.001 \\
(0.006)\end{array}$ & $\begin{array}{c}0.039 * * * \\
(0.008)\end{array}$ \\
\hline Nonroutine Manual & $\begin{array}{c}0.037 * * \\
(0.018)\end{array}$ & $\begin{array}{c}-0.139 * * * \\
(0.031)\end{array}$ \\
\hline \multicolumn{3}{|l|}{ Demographics: } \\
\hline Years of Schooling & $\begin{array}{c}0.011 \\
(0.012)\end{array}$ & $\begin{array}{c}0.055^{* * *} \\
(0.012)\end{array}$ \\
\hline Annual Hours Worked Last Year & $\begin{array}{c}-0.998 * * * \\
(0.077)\end{array}$ & $\begin{array}{c}0.418^{* * *} \\
(0.109)\end{array}$ \\
\hline Female & $\begin{array}{c}-0.366^{* * *} \\
(0.049)\end{array}$ & $\begin{array}{c}-0.734 * * * \\
(0.048)\end{array}$ \\
\hline Observations & 230,330 & 230,330 \\
\hline Psuedo R-squared & 0.99 & 0.99 \\
\hline \multicolumn{3}{|c|}{$\begin{array}{l}\text { Notes: This table reports multinomial logit estimates of the probability that a worker between the ages of } 25 \\
\text { and } 55 \text { is unincorporated or incorporated self-employed. Salaried workers are the excluded category. The } \\
\text { regressions also include state, year, and race fixed effects, as well as a quartic for experience. The sample } \\
\text { excludes people who do not work either as salaried or self-employed, people with missing data on relevant } \\
\text { demographics and labor market outcomes, and people living within group quarters. The analyses include the } \\
\text { sub-sample of CPS observations for which we have a matched, two-year panel over the work years } 1995 \\
\text { through } 2012 \text {. Data on job task requirements are from Autor, Levy, and Murnane (2003), who link data from } \\
\text { the Dictionary of Occupational Titles with the occupational categories in the CPS. Nonroutine Analytical } \\
\text { measures the degree to which the task demands analytical flexibility, creativity, and generalized problem- } \\
\text { solving, including tasks such as forming and testing hypotheses, making medical diagnoses, etc. Nonroutine } \\
\text { Direction, Control, Planning measures the degree to which the task demands complex interpersonal } \\
\text { communications such as persuading, selling, and managing others. Nonroutine Manual measures the degree } \\
\text { to which the task demands eye, hand, and foot coordination, including landscaping, truck driving, carpentry, } \\
\text { plumbing, and piloting a commercial airline. Heteroskedasticity robust standard errors clustered at the year- } \\
\text { level are in parentheses, where } * * * \text {, and } * * * \text { indicate significance at the } 10 \%, 5 \% \text {, and } 1 \% \text { levels } \\
\text { respectively. }\end{array}$} \\
\hline
\end{tabular}


Table 4: Top and Bottom Industries by Nonroutine Job Task Requirements, CPS

\section{Nonroutine Analytical Industry \\ Nonroutine Direction, \\ Control, Planning Industry \\ Nonroutine Manual Industry}

Panel A: Top Industries

\begin{tabular}{|c|c|c|c|c|c|}
\hline \multicolumn{6}{|l|}{ Engineering and architectural } \\
\hline services & 6.56 & Educational services & 6.23 & Taxicab service & 4.26 \\
\hline Accounting, auditing, and & & \multicolumn{4}{|l|}{ Engineering and architectural } \\
\hline bookkeeping services & 5.84 & services & 6.05 & Trucking service & 3.52 \\
\hline \multicolumn{2}{|l|}{ Miscellaneous professional and } & \multicolumn{4}{|l|}{ Accounting, auditing, and } \\
\hline related services & 5.34 & bookkeeping services & 5.05 & Street railways and bus lines & 3.14 \\
\hline \multicolumn{6}{|l|}{ Security and commodity brokerage } \\
\hline and investment companies & 5.16 & Advertising & 4.93 & Logging & 2.66 \\
\hline Aircraft and parts & 5.08 & Theaters and motion pictures & 4.90 & Water transportation & 2.16 \\
\hline \multicolumn{6}{|c|}{ Panel B: Bottom Industries } \\
\hline Private households & 0.99 & Private households & 0.45 & Legal services & 0.07 \\
\hline Logging & 2.07 & Taxicab service & 0.57 & $\begin{array}{l}\text { Accounting, auditing, and } \\
\text { bookkeeping services }\end{array}$ & 0.09 \\
\hline Taxicab service & 2.18 & Postal service & 0.98 & Insurance & 0.16 \\
\hline Trucking service & 2.19 & Trucking service & 1.04 & $\begin{array}{l}\text { Security and commodity } \\
\text { brokerage and investment }\end{array}$ & 0.18 \\
\hline Laundering, cleaning, and dyeing & 2.30 & & & & \\
\hline services & & Legal services & 1.25 & Banking and credit agencies & 0.21 \\
\hline \multicolumn{6}{|c|}{ Notes: This table reports the top and the bottom five industries in each of three categories of job task requirements from the Dictionary of } \\
\hline \multicolumn{6}{|c|}{ Occupational Titles. For each industry, we compute the hours-weighted job task requirements of people working in the industry over the work years } \\
\hline \multicolumn{6}{|c|}{1995 through 2012. We exclude industries with less than 1000 observations. We do this for three categories of skills for each: (1) Nonroutine Analytical } \\
\hline \multicolumn{6}{|c|}{ measures the degree to which the task demands analytical flexibility, creativity, and generalized problem-solving, including tasks such as forming and } \\
\hline \multicolumn{5}{|c|}{ complex interpersonal communications such as persuading, selling, and managing others; and (3) Nonroutine Manual measures the degree to which } & testing hypotheses, making medical diagnoses, etc.; (2) Nonroutine Direction, Control, Planning measures the degree to which the task demands \\
\hline the task demands eye, hand, and foot $\mathrm{c}$ & & cluding landscaning truck driving & & & \\
\hline
\end{tabular}


Table 5: Differences in Task Requirements of Incorporated and Unincorporated Businesses CPS Panel

\begin{tabular}{|c|c|c|c|c|c|c|}
\hline & \multicolumn{6}{|c|}{ The Task Requirements of the Industry of the New Business: } \\
\hline & \multicolumn{2}{|c|}{$\begin{array}{l}\text { Nonroutine Analytical } \\
\text { Industry }\end{array}$} & \multicolumn{2}{|c|}{$\begin{array}{l}\text { Nonroutine Direction, } \\
\text { Control, Planning }\end{array}$} & \multicolumn{2}{|c|}{$\begin{array}{c}\text { Nonroutine Manual } \\
\text { Industry }\end{array}$} \\
\hline & $\begin{array}{c}\text { by } \\
\text { Industry }\end{array}$ & $\begin{array}{c}\text { by } \\
\text { Industry- } \\
\text { Firm Size }\end{array}$ & $\begin{array}{c}\text { by } \\
\text { Industry }\end{array}$ & $\begin{array}{c}\text { by } \\
\text { Industry- } \\
\text { Firm Size }\end{array}$ & $\begin{array}{c}\text { by } \\
\text { Industry }\end{array}$ & $\begin{array}{c}\text { by } \\
\text { Industry- } \\
\text { Firm Size }\end{array}$ \\
\hline & $(1)$ & $(2)$ & $(3)$ & $(4)$ & $(5)$ & $(6)$ \\
\hline $\begin{array}{l}\text { New Incorporated } \\
\text { Business Owner }\end{array}$ & $\begin{array}{c}0.094 * * * \\
(0.013)\end{array}$ & $\begin{array}{c}0.062 * * * \\
(0.013)\end{array}$ & $\begin{array}{c}0.157^{* * *} \\
(0.022)\end{array}$ & $\begin{array}{c}0.161^{* * *} \\
(0.027)\end{array}$ & $\begin{array}{c}-0.172 * * * \\
(0.015)\end{array}$ & $\begin{array}{c}-0.084 * * * \\
(0.014)\end{array}$ \\
\hline \multicolumn{7}{|l|}{ Other regressors: } \\
\hline Education \& experience & No & Yes & No & Yes & No & Yes \\
\hline Year and state effects & No & Yes & No & Yes & No & Yes \\
\hline Firm size effects & No & Yes & No & Yes & No & Yes \\
\hline Observations & 14687 & 14687 & 14687 & 14687 & 14687 & 14687 \\
\hline R-square & 0.004 & 0.193 & 0.006 & 0.112 & 0.013 & 0.169 \\
\hline \multicolumn{7}{|c|}{$\begin{array}{l}\text { Notes: This table reports regressions of the job task requirements of the businesses of newly self-employed individuals } \\
\text { on whether the business is incorporated or unincorporated. For each industry, we compute the hours-weighted job task } \\
\text { requirements of people working in the industry over the work years } 1995 \text { through } 2012 \text {. We do this for three categories } \\
\text { of skills for each: (1) Nonroutine Analytical measures the degree to which the task demands analytical flexibility, } \\
\text { creativity, and generalized problem-solving, including tasks such as forming and testing hypotheses, making medical } \\
\text { diagnoses, etc.; (2) Nonroutine Direction, Control, Planning measures the degree to which the task demands complex } \\
\text { interpersonal communications such as persuading, selling, and managing others; and (3) Nonroutine Manual measures } \\
\text { the degree to which the task demands eye, hand, and foot coordination, including landscaping, truck driving, carpentry, } \\
\text { plumbing, and piloting a commercial airline. To the businesses of newly self-employed individuals, we assign the } \\
\text { hours-weighted job task requirements of the business's industry. To examine the newly self-employed, we restrict the } \\
\text { matched two-year CPS panel sample to individuals who were full-time, full-year salaried workers in year t- } 1 \text { and who } \\
\text { became self-employed in year t. Heteroskedasticity robust standard errors clustered at the year-level are in parentheses, } \\
\text { where } *, * * \text {, and } * * * \text { indicate significance at the } 10 \%, 5 \% \text {, and } 1 \% \text { levels respectively. }\end{array}$} \\
\hline
\end{tabular}




\begin{tabular}{|c|c|c|c|c|c|}
\hline & \multirow[t]{2}{*}{ All } & \multirow[t]{2}{*}{ Salaried } & \multicolumn{3}{|c|}{ Self-Employed } \\
\hline & & & All & Uninc. & Inc. \\
\hline \multicolumn{6}{|l|}{ A. Family background } \\
\hline Mother's Education & 11.7 & 11.7 & 12.0 & 11.8 & 12.6 \\
\hline Father's Education & 11.9 & 11.9 & 12.2 & 12.1 & 12.7 \\
\hline Two parents family (14) & 0.76 & 0.76 & 0.77 & 0.76 & 0.83 \\
\hline Family Income in 1979 & $\$ 57,431$ & $\$ 57,140$ & $\$ 60,182$ & $\$ 57,567$ & $\$ 70,317$ \\
\hline \multicolumn{6}{|l|}{ B. Cognitive and non-cognitive traits } \\
\hline AFQT & 50.1 & 50.0 & 51.4 & 50.4 & 55.2 \\
\hline Rotter Locus of Control (standardized) & -0.10 & -0.09 & -0.18 & -0.16 & -0.28 \\
\hline Rosenberg Self-Esteem (standardized) & 0.08 & 0.07 & 0.10 & 0.06 & 0.27 \\
\hline Illicit Activity Index (standardized) & 0.01 & 0.00 & 0.12 & 0.10 & 0.20 \\
\hline Force (raw) & 0.04 & 0.04 & 0.06 & 0.06 & 0.08 \\
\hline Steal 50 or less (raw) & 0.21 & 0.21 & 0.24 & 0.23 & 0.26 \\
\hline Stopped by Police (raw) & 0.19 & 0.18 & 0.22 & 0.21 & 0.26 \\
\hline \multicolumn{6}{|l|}{ C. Self-designation and invention (2010) } \\
\hline Entrepreneur (residual standardized) & 0.00 & -0.08 & 0.80 & 0.69 & 1.20 \\
\hline Applied for Patent (residual standardized) & 0.00 & -0.01 & 0.08 & 0.03 & 0.28 \\
\hline \multicolumn{6}{|c|}{$\begin{array}{l}\text { Notes: This table provides summary statistics from the NLSY79 on people who are at least } 25 \text { years old and in the work force. This } \\
\text { covers work years } 1982 \text { through } 2012 \text {. Family background and data on cognitive and non-cognitive traits are measured in } 1979 \text { and in } \\
\text { 1980, which is before anyone in the sample enters prime age. Mother's Education and Father's Education are the number of years of } \\
\text { education of the person's mother and father. Two-Parents Family (14) equals one if the person at the age of } 14 \text { had two parents living at } \\
\text { home and zero otherwise. Family Income in } 1979 \text { is the income of the person's family in } 1979 \text {. AFQT is a measure of cognitive ability; } \\
\text { Rotter Locus of Control measures the degree to which a person feels luck, fate, and external factors control events relative to the extent } \\
\text { that internal factors give the person self-determination over his or life, such that negative values imply a greater sense of internal } \\
\text { control; and Rosenberg Self-Esteem measures the self-esteem of the individual based on a psychometric test. The Illicit Index, which is } \\
\text { computed in 1980, measures the degree to which an individual engaged in an array of disruptive, aggressive, risk-taking, and illicit } \\
\text { activities, including taking things by force (Force), stealing, including items less that } \$ 50 \text { (Steal 50 or less), and whether the person was } \\
\text { stopped by the police (Stopped by Police). Entrepreneur is based on the } 2010 \text { survey question, "Do you consider yourself to be an } \\
\text { entrepreneur (where an entrepreneur is defined by the questioner as someone who launches a business enterprise, usually with } \\
\text { considerable initiative and risk)?" We obtain the residuals of a regression of Entrepreneur on education AFQT, Rosenberg Self-Esteem, } \\
\text { Rotter Locus of Control, the Illicit Index, and year of birth and then standardizing these residuals to have zero mean and a standard } \\
\text { deviation of one. Applied for Patent is similarly calculated based on the } 2010 \text { survey question, "Has anyone, including yourself, ever } \\
\text { applied for a patent for work that you significantly contributed to? }\end{array}$} \\
\hline
\end{tabular}


Table 7: Selection into Employment Types on Cognitive, Noncognitive, and Family Traits, NLSY79

Self-Employment by Type:

All (vs

Salaried)

(1)

\section{Cognitive and Non-cognitive Traits}

AFQT

0.076
$(0.115)$

Illicit

$0.078 * * *$
$(0.027)$

Rosenberg Score

0.031

(0.029)

Rotter Score

$$
-0.097 * * *
$$

(0.028)

AFQT*Illicit

\section{Demographics}

Black

Hispanic

Female

$\begin{array}{cccc}-0.560 * * * & -0.504 * * * & -0.501 * * * & -0.537 * * * \\ (0.072) & (0.075) & (0.075) & (0.077) \\ -0.318 * * * & -0.332 * * * & -0.328 * * * & -0.273 * * * \\ (0.076) & (0.079) & (0.079) & (0.085) \\ -0.340 * * * & -0.260 * * * & -0.261 * * * & -0.266 * * * \\ (0.055) & (0.059) & (0.059) & (0.059)\end{array}$

$-0.887 * * *$

(0.164)

$-0.898 * * *$

$-0.777 * * *$

$-0.163 \quad-0.151$
$(0.104)$

$0.306^{*}$

$0.327^{* *}$

(0.157)

(0.163)

(0.165)

(0.168)

$-0.253$

$-0.260$

0.043

(0.166)

(0.167)

(0.176)

$-0.727 * * *$

$-0.724 * * *$

$-0.708 * * *$

(0.119)

(0.119)

(0.119)

\section{Family Traits}

Family Income

$-0.070$

(0.099)

$0.449 * * *$

0.017

$0.086 * * *$

(0.014)

(0.027)

0.010

0.010

(0.011)

(0.021)

Father Education

$\begin{array}{llll}125166 & 125166 & 125166 & 125166 \\ 0.0276 & 0.0302 & 0.0306 & 0.0340\end{array}$

125166

125166

125166

Observations

Pseudo R-Square

0.0302

0.0306

0.0340

Note: This table reports multinomial logit estimates of the probability that an individual, 25 years of age or older, is self-employed, incorporated selfemployed, or unincorporated self-employed, where salaried employment is the excluded category. All dummy variables are defined exclusively. AFQT is a measure of cognitive ability, which ranges from 1 to 100, and is divided by 100 in these analyses. The Illicit Index, which was computed in 1980, measures the degree to which an individual engaged in an array of aggressive, risk-taking, and disruptive activities. It is standardized to equal zero for the NLSY79 population. Rotter Locus of Control measures the degree to which a person feels luck, fate, and external factors control events relative to the extent that internal factors give the person self-determination over his or life, such that negative values imply a greater sense of internal control; and Rosenberg Self-Esteem measures the self-esteem of the individual based on a psychometric test. Family Income in 1979 is the income of the person's family in 1979, divided by $\$ 100,000$. Though unreported in the table, all regressions control for year of birth, a dummy variable of whether both parents were living at the home of the individual at the age of 14 , and dummy variables for individuals with missing family income (for which we impute the average value in the sample) and missing parental education (for which we impute values based on the other parent's education and the average for the sample if no parental education is reported). We exclude observations in which the person is neither salaried nor self-employed and observations with missing demographics (gender, race and ethnicity, schooling) or missing values for AFQT, Rosenberg Self-Esteem, Rotter Locus of Control, and Illicit. Reported standard errors (in parentheses) are corrected for heteroskedasticity and clustered by individual. The symbols $* * *, * *$, and $*$ signify significance at the one, five, and ten percent levels respectively. 
Self-Employment by Type: SelfEmployed

(1)

Adjusted wages

Illicit

Adjusted wages * Illicit

\section{Controlling for}

AFQT, Rotter and
Rosenberg scores

Family income and

parents' education

Education and

experinece

Sample

Observations

Pseudo R-Square

(0.123)

Yes

Yes

33405

0.0291
Unincorporated

(2)

(3)

(4)

$-0.359 * * *$

$-0.648 * * * \quad-0.662 * * *$

(0.122)

(0.135)

$-0.843^{* * *}$

(0.173)

0.074
$(0.054)$

0.069

(0.069)

(0.049)

0.021

$-0.053$

(0.074)

(0.109)

Yes

Yes

Yes

Yes

Yes

Yes

Yes

Yes

Yes

All

FTFY

33405

33405

0.0465

23957

0.0530
(5)

(6)

(7)

$0.691 * * \quad 0.559 * *$

0.426

(0.285)

(0.277)

(0.318)

$\begin{array}{cc}0.132 * & 0.103 \\ (0.072) & (0.074)\end{array}$

0.118

(0.085)

$\begin{array}{cc}0.398 * * & 0.429 * * \\ (0.164) & (0.194)\end{array}$

Yes

Yes

Yes

Yes

Yes

Yes

Yes

Yes

Yes

Note: This table reports multinomial logit estimates of the probability that an individual, 25 years of age or older, is self-employed, incorporated self-employed, or unincorporated self-employed, where salaried employment is the excluded category. All dummy variables are defined exclusively. Adjusted Wages are computed as the person fixed effect from a Mincerian log wage regression when people work as full-time, full-year salaried workers, where the wage regression is estimated over the full sample period. The Illicit Index, which was computed in 1980, measures the degree to which an individual engaged in an array of aggressive, risk-taking, and disruptive activities. It is standardized to equal zero for the NLSY79 population. Rotter Locus of Control measures the degree to which a person feels luck, fate, and external factors control events relative to the extent that internal factors give the person self-determination over his or life, such that negative values imply a greater sense of internal control; and Rosenberg Self-Esteem measures the self-esteem of the individual based on a psychometric test. Family Income in 1979 is the income of the person's family in 1979, divided by $\$ 100,000$. Though unreported in the table, all regressions control for year of birth, the year of the survey, a dummy variable of whether both parents were living at the home of the individual at the age of 14, educational attainment (six categories), a quartic for potential experience and dummy variables for individuals with missing family income (for which we impute the average value in the sample) and missing parental education (for which we impute values based on the other parent's education and the average for the sample if no parental education is reported). We exclude observations in which the person is neither salaried nor self-employed and observations with missing demographics (gender, race and ethnicity, schooling) or missing values for AFQT, Rosenberg Self-Esteem, Rotter Locus of Control, and Illicit. These regressions only include white (non-Hispanic) males who are at least 25 years old. Reported standard errors (in parentheses) are corrected for heteroskedasticity and clustered by individual. The symbols $* * *, * *$, and * signify significance at the one, five, and ten percent levels respectively. 
Table 9: Differences in Job Task Requirements of Businesses by Individual Traits, NLSY79

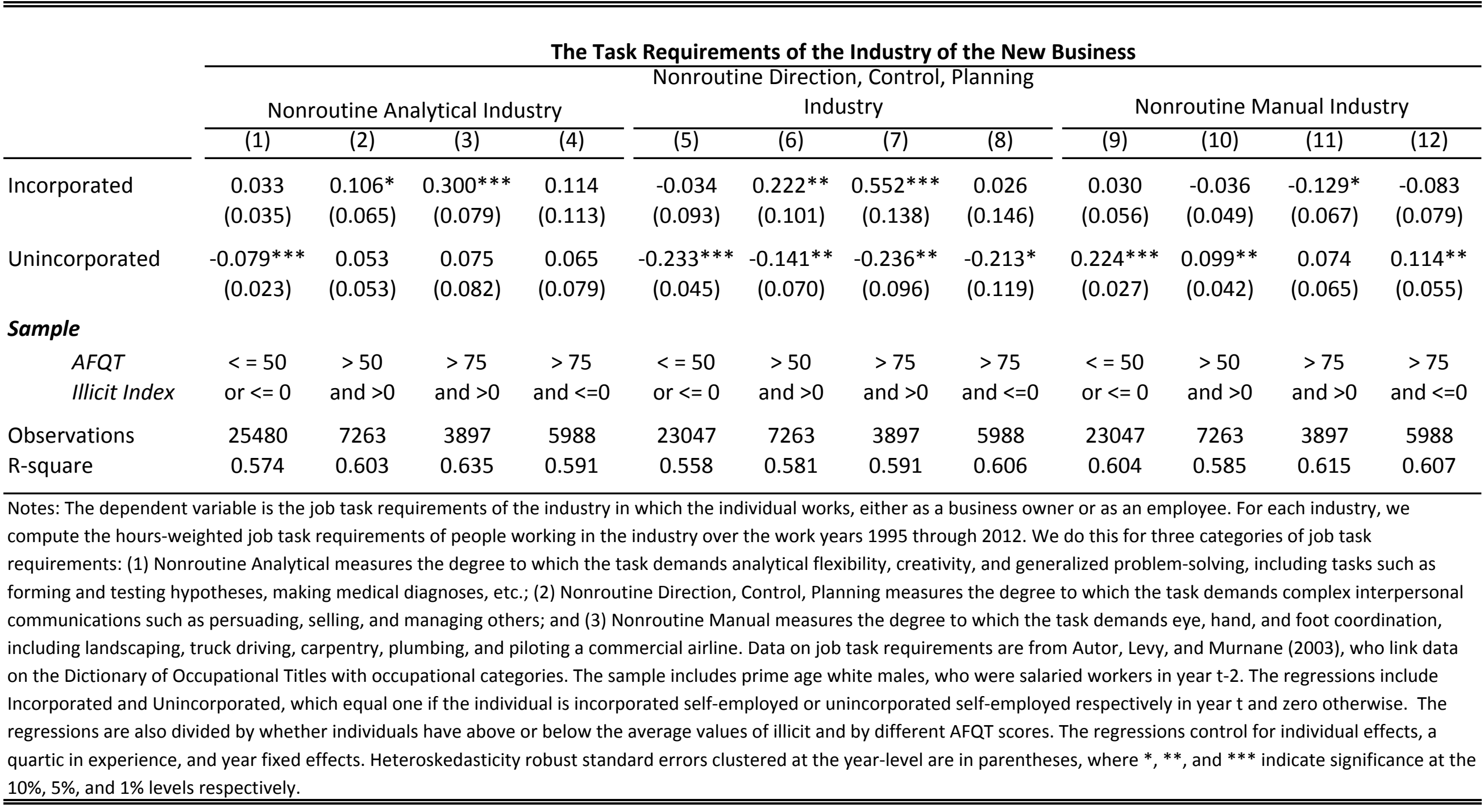


Table 10: Earnings and Individual Effects, CPS

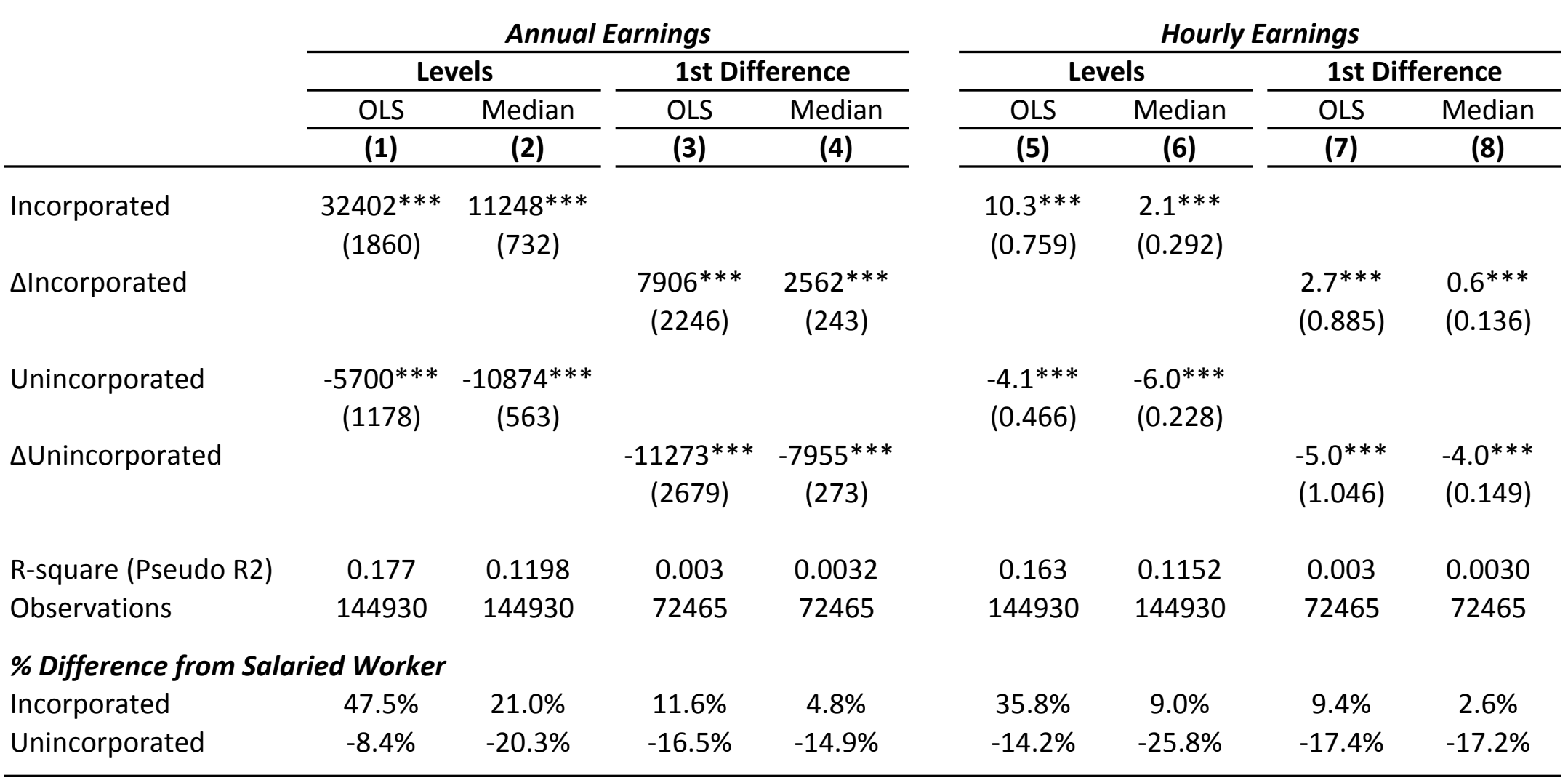

Notes: This table reports regression results of both annual earnings and hourly earnings on employment type using data from the CPS for the subsample of observations for which we have a matched, two-year panel. The sample covers work years 1995 through 2012. The table provides estimated coefficients from earnings regressions in levels and and first-differences, using both OLS and median regressions. In the levels regression, there are two key, reported explanatory variables: Incorporated equals one if the person is incorporated self-employed and zero otherwise;

Unincorporated equals one if the person is unincorporated self-employed and zero otherwise. In the first-differences regressions, we examine the change in earnings and focus on two explanatory variables: $\Delta$ Incorporated equals the change in incorporated self-employment status;

$\Delta$ Unincorporated equals the change in the unincorporated self-employment status. All of the the regressions control for year and state fixed effects, as well as standard Mincerian characteristics: dummy variables for six education categories and a quartic expression for potential work experience. The sample includes white males, who are full-time workers between the ages of 25 and 55, and excludes persons who do not work either as salaried or self-employed and people with missing data on relevant demographics. Heteroskedasticity robust standard errors clustered at the year-level are in parentheses. where ***, and $* * *$ indicate significance at the $10 \% .5 \%$ and $1 \%$ levels respectivelv. 
Table 11: Earnings and Individual Effects, NLSY79

\begin{tabular}{|c|c|c|c|c|c|c|c|c|}
\hline \multirow[t]{3}{*}{ Panel A: Annual Earnings } & \multicolumn{4}{|c|}{ OLS } & \multicolumn{4}{|c|}{ MEDIAN } \\
\hline & \multicolumn{2}{|c|}{ Levels } & \multicolumn{2}{|c|}{ 1st Difference } & \multicolumn{2}{|c|}{ Levels } & \multicolumn{2}{|c|}{ 1st Difference } \\
\hline & (1) & (2) & (3) & $(4)$ & (5) & (6) & (7) & (8) \\
\hline Incorporated & $\begin{array}{c}45926 * * * \\
(6546)\end{array}$ & $\begin{array}{c}17446 * * * \\
(3885)\end{array}$ & & & $\begin{array}{c}23941 * * * \\
(3459)\end{array}$ & $\begin{array}{c}5378 * * * \\
(621)\end{array}$ & & \\
\hline$\Delta$ Incorporated & & & $\begin{array}{c}12592 * * \\
(5748)\end{array}$ & $\begin{array}{c}11219 * * \\
(5201)\end{array}$ & & & $\begin{array}{c}3953 * * * \\
(519)\end{array}$ & $\begin{array}{c}3351^{* * *} \\
(364)\end{array}$ \\
\hline Unincorporated & $\begin{array}{c}8893 * * * \\
(2961)\end{array}$ & $\begin{array}{c}5417^{* * *} \\
(1809)\end{array}$ & & & $\begin{array}{c}-687 \\
(1042)\end{array}$ & $\begin{array}{l}-367 \\
(478)\end{array}$ & & \\
\hline$\Delta$ Unincorporated & & & $\begin{array}{c}2580 \\
(2183)\end{array}$ & $\begin{array}{c}2563 \\
(2473)\end{array}$ & & & $\begin{array}{l}-728 * \\
(393)\end{array}$ & $\begin{array}{l}-399 \\
(327)\end{array}$ \\
\hline \multicolumn{9}{|c|}{ \% Difference from Salaried Worker } \\
\hline Incorporated & $75 \%$ & $29 \%$ & $21 \%$ & $18 \%$ & $49 \%$ & $11 \%$ & $8 \%$ & $7 \%$ \\
\hline Unincorporated & $15 \%$ & $9 \%$ & $4 \%$ & $4 \%$ & $-1 \%$ & $-1 \%$ & $-1 \%$ & $-1 \%$ \\
\hline Individual Fixed Effects & No & Yes & No & Yes & No & Yes & No & Yes \\
\hline Observations & 23657 & 23657 & 17479 & 17479 & 23657 & 23657 & 17479 & 17479 \\
\hline R-square & 0.253 & 0.631 & 0.011 & 0.082 & 0.132 & 0.111 & 0.016 & 0.010 \\
\hline \multirow[t]{3}{*}{ Panel B: Hourly Earnings } & \multicolumn{4}{|c|}{ OLS } & \multicolumn{4}{|c|}{ MEDIAN } \\
\hline & \multicolumn{2}{|c|}{ Levels } & \multicolumn{2}{|c|}{ 1st Difference } & \multicolumn{2}{|c|}{ Levels } & \multicolumn{2}{|c|}{ 1st Difference } \\
\hline & (9) & $(10)$ & $(11)$ & $(12)$ & $(13)$ & $(14)$ & $(15)$ & $(16)$ \\
\hline Incorporated & $\begin{array}{c}13.141^{* * *} \\
(2.250)\end{array}$ & $\begin{array}{c}4.384 * * * \\
(1.407)\end{array}$ & & & $\begin{array}{c}5.317^{* * *} \\
(1.094)\end{array}$ & $\begin{array}{c}0.978 * * * \\
(0.311)\end{array}$ & & \\
\hline$\Delta$ Incorporated & & & $\begin{array}{c}4.168 * * \\
(1.975)\end{array}$ & $\begin{array}{c}3.846 * * \\
(1.825)\end{array}$ & & & $\begin{array}{c}1.350 * * * \\
(0.225)\end{array}$ & $\begin{array}{c}0.928 * * * \\
(0.222)\end{array}$ \\
\hline Unincorporated & $\begin{array}{c}0.376 \\
(1.062)\end{array}$ & $\begin{array}{c}0.739 \\
(0.665)\end{array}$ & & & $\begin{array}{c}-2.737^{* * *} \\
(0.356)\end{array}$ & $\begin{array}{c}-0.849 * * * \\
(0.224)\end{array}$ & & \\
\hline$\Delta$ Unincorporated & & & $\begin{array}{c}0.013 \\
(0.808)\end{array}$ & $\begin{array}{c}0.004 \\
(0.893)\end{array}$ & & & $\begin{array}{c}-0.739 * * * \\
(0.185)\end{array}$ & $\begin{array}{c}-0.554 * * * \\
(0.175)\end{array}$ \\
\hline \% Difference from Salaried & & & & & & & & \\
\hline Incorporated & $52 \%$ & $18 \%$ & $17 \%$ & $15 \%$ & $26 \%$ & $5 \%$ & $7 \%$ & $5 \%$ \\
\hline Unincorporated & $2 \%$ & $3 \%$ & $0 \%$ & $0 \%$ & $-13 \%$ & $-4 \%$ & $-4 \%$ & $-3 \%$ \\
\hline Individual Fixed Effects & No & Yes & No & Yes & No & Yes & No & Yes \\
\hline Observations & 23657 & 23657 & 17479 & 17479 & 23657 & 23657 & 17479 & 17479 \\
\hline R-square & 0.255 & 0.625 & 0.011 & 0.078 & 0.136 & 0.110 & 0.012 & 0.006 \\
\hline
\end{tabular}

Notes: This table reports regression results of both annual earnings and hourly earnings on employment type using data from the NLSY79 for years 1982 through 2012. The table provides estimated coefficients from earnings regressions in levels and and first-differences, using both OLS and median regressions, and both including and excluding individual fixed effects. In the levels regression, there are two key, reported explanatory variables: Incorporated equals one if the person is incorporated self-employed and zero otherwise; Unincorporated equals one if the person is unincorporated self-employed and zero otherwise. In the first-differences regressions, we examine the change in earnings and focus on two explanatory variables: $\Delta$ Incorporated equals the change in incorporated self-employment status; $\Delta$ Unincorporated equals the change in the unincorporated self-employment status. All of the the regressions control for year fixed effects as well as standard Mincerian characteristics: dummy variables for six education categories and a quartic expression for potential work experience. The sample includes white males, who are full-time workers between the ages of 25 and 55, and excludes persons who do not work either as salaried or self-employed and people with missing data on relevant demographics. When examining \% differences from salaried workers, the statistics are based on the means for salaried workers for the OLS regressions and the medians for salaried workers in the median regressions. Heteroskedasticity robust standard errors clustered at the year-level are in parentheses, where *, **, and *** indicate significance at the $10 \%, 5 \%$, and $1 \%$ levels respectively. 


\begin{tabular}{|c|c|c|c|c|c|c|c|c|}
\hline \multirow[t]{2}{*}{ Panel A: Annual Earnings } & \multicolumn{3}{|c|}{ OLS } & \multirow[b]{2}{*}{ (4) } & \multicolumn{4}{|c|}{ MEDIAN } \\
\hline & (1) & $(2)$ & (3) & & (5) & (6) & (7) & (8) \\
\hline Incorporated & $\begin{array}{c}17446^{* * *} \\
(3885)\end{array}$ & & & & $\begin{array}{c}5378^{* * *} \\
(621)\end{array}$ & & & \\
\hline Unincorporated & $\begin{array}{c}5417^{* * *} \\
(1809)\end{array}$ & & & & $\begin{array}{l}-367 \\
(478)\end{array}$ & & & \\
\hline Spell starts as incorporated & & $\begin{array}{c}14064 * * * \\
(4112)\end{array}$ & $\begin{array}{c}12309 * * * \\
(3271)\end{array}$ & & & $\begin{array}{l}5339 * * * \\
(564)\end{array}$ & $\begin{array}{l}4604^{* * * *} \\
(691)\end{array}$ & \\
\hline Spell starts as unincorporated & & $\begin{array}{c}7194 * * * \\
(1831)\end{array}$ & $\begin{array}{c}4995^{* * *} \\
(1620)\end{array}$ & & & $\begin{array}{l}-326 \\
(435)\end{array}$ & $\begin{array}{l}-78 \\
(464)\end{array}$ & \\
\hline 1st year of 1st spell incorporated & & & & $\begin{array}{c}11186^{* * *} \\
(2961)\end{array}$ & & & & $\begin{array}{l}4334^{* * *} \\
(399)\end{array}$ \\
\hline 1st year of 1st spell unincorporated & & & & $\begin{array}{c}1846 \\
(1655)\end{array}$ & & & & $\begin{array}{l}-1467^{* * *} \\
(356)\end{array}$ \\
\hline \multicolumn{9}{|l|}{ \% Difference from Salaried Worker } \\
\hline Incorporated & $29 \%$ & $23 \%$ & $20 \%$ & $18 \%$ & $11 \%$ & $11 \%$ & $9 \%$ & $9 \%$ \\
\hline Unincorporated & $9 \%$ & $12 \%$ & $8 \%$ & $3 \%$ & $-1 \%$ & $-1 \%$ & $0 \%$ & $-3 \%$ \\
\hline Individual effects & Yes & Yes & Yes & Yes & Yes & Yes & Yes & Yes \\
\hline Weighted by inverse of years in spell & No & No & Yes & Yes & No & No & Yes & Yes \\
\hline Observations & 23657 & 23657 & 23657 & 23657 & 23657 & 23657 & 23657 & 23657 \\
\hline Spells & 3553 & 3553 & 3553 & 3553 & 3553 & 3553 & 3553 & 3553 \\
\hline R-square ( Pseudo R2) & 0.63 & 0.63 & 0.63 & 0.63 & 0.111 & 0.111 & 0.111 & 0.080 \\
\hline \multirow[t]{2}{*}{ Panel B: Hourly Earnings } & \multicolumn{3}{|c|}{ OLS } & & \multicolumn{4}{|c|}{ MEDIAN } \\
\hline & (9) & $(10)$ & (11) & $(12)$ & (13) & (14) & $(15)$ & $(16)$ \\
\hline Incorporated & $\begin{array}{c}4.384^{* * *} \\
(1.407)\end{array}$ & & & & $\begin{array}{c}0.978^{* * *} \\
(0.311)\end{array}$ & & & \\
\hline Unincorporated & $\begin{array}{c}0.739 \\
(0.665)\end{array}$ & & & & $\begin{array}{c}-0.849 * * * \\
(0.224)\end{array}$ & & & \\
\hline Spell starts as incorporated & & $\begin{array}{c}3.520^{* *} \\
(1.527)\end{array}$ & $\begin{array}{c}3.655^{* * *} \\
(1.194)\end{array}$ & & & $\begin{array}{l}1.097^{* * *} \\
(0.311)\end{array}$ & $\begin{array}{l}0.925^{* * *} \\
(0.335)\end{array}$ & \\
\hline Spell starts as unincorporated & & $\begin{array}{l}1.213^{*} \\
(0.670)\end{array}$ & $\begin{array}{c}0.691 \\
(0.611)\end{array}$ & & & $\begin{array}{l}-0.905^{* * *} \\
(0.228)\end{array}$ & $\begin{array}{l}\text { t-0.844*** } \\
(0.225)\end{array}$ & \\
\hline 1st year of 1st spell incorporated & & & & $\begin{array}{c}3.612 * * * \\
(1.072)\end{array}$ & & & & $\begin{array}{l}0.667^{* * *} \\
(0.233)\end{array}$ \\
\hline 1st year of 1st spell unincorporated & & & & $\begin{array}{l}-0.300 \\
(0.623)\end{array}$ & & & & $\begin{array}{l}-0.858^{* * *} \\
(0.143)\end{array}$ \\
\hline \multicolumn{9}{|l|}{ \% Difference from Salaried Worker } \\
\hline Incorporated & $18 \%$ & $14 \%$ & $15 \%$ & $14 \%$ & $5 \%$ & $5 \%$ & $5 \%$ & $3 \%$ \\
\hline Unincorporated & $3 \%$ & $5 \%$ & $3 \%$ & $-1 \%$ & $-4 \%$ & $-4 \%$ & $-4 \%$ & $-4 \%$ \\
\hline Individual effects & Yes & Yes & Yes & Yes & Yes & Yes & Yes & Yes \\
\hline Weighted by inverse of years in spell & No & No & Yes & Yes & No & No & Yes & Yes \\
\hline Observations & 23657 & 23657 & 23657 & 23657 & 23657 & 23657 & 23657 & 23657 \\
\hline Spells & 3553 & 3553 & 3553 & 3553 & 3553 & 3553 & 3553 & 3553 \\
\hline R-square ( Pseudo R2) & 0.625 & 0.625 & 0.623 & 0.623 & 0.110 & 0.110 & 0.110 & 0.077 \\
\hline
\end{tabular}


Notes: This table reports regression results of both annual earnings and hourly earnings on employment type using data from the NLSY79 for years 1982 through 2012. Panel A provides results on annual earning, while Panel B examines hourly earnings. Incorporated equals one if the person is incorporated self-employed and zero otherwise. Unincorporated equals one if the person is unincorporated self-employed and zero otherwise. An employment spell is the full set of consecutive years as either a salaried or self-employed worker. Since we only consider fulltime, full-year workers, individuals are either salaried or a self-employed in each period. A self-employment spell is the full set of consecutive years in which a person is self-employed (either incorporated or unincorporated). Spell starts incorporated equals one for each year of a selfemployment spell if the person starts the self-employment spell as an incorporated business owner and zero otherwise. Spell starts unincorporated is defined analogously. 1st year of 1st spell incoporated equals one for each year of all of the years an individual is selfemployed if in the first year of the first employment spell the individual is incoprorated self-employed and zero otherwise. 1st year of 1st spell unincoporated equals one for each year of all of the years an individual is self-employed if in the first year of the first employment spell the individual is unincoprorated self-employed and zero otherwise. The regressions control for individual effects, year effects, and experience. In the indicated regressions, the observations are weighted by the inverse of the number of years in the employment spell to give equal weight to each spell. Heteroskedasticity robust standard errors clustered at the year-level are in parentheses, where $*,{ }^{* *}$, and ${ }^{* * *}$ indicate significance at the $10 \%, 5 \%$, and $1 \%$ levels respectively. 
Table 13: The Change in Median Earnings Differentiating by "Smart and Illicit," NLSY79

\begin{tabular}{|c|c|c|c|c|}
\hline & $(1)$ & (2) & $(3)$ & $(4)$ \\
\hline$\Delta$ Incorporated & $\begin{array}{l}716^{* *} \\
(285)\end{array}$ & $\begin{array}{c}6996 * * * \\
(547)\end{array}$ & & \\
\hline$\Delta$ Unincorporated & $\begin{array}{c}105 \\
(426)\end{array}$ & $\begin{array}{c}-1895^{* *} \\
(807)\end{array}$ & & \\
\hline$\Delta$ Self-Employed $x$ Nonroutine Cognitive Industry & & & $\begin{array}{c}-3234 * * * \\
(955)\end{array}$ & $\begin{array}{c}8163 * * * \\
(1052)\end{array}$ \\
\hline$\Delta$ Self-Employed & & & $\begin{array}{c}1155^{* *} \\
(452)\end{array}$ & $\begin{array}{c}-1550^{*} \\
(937)\end{array}$ \\
\hline Nonroutine Cognitive Industry & & & $\begin{array}{c}1139 * * * \\
(193)\end{array}$ & $\begin{array}{c}1563 * * * \\
(361)\end{array}$ \\
\hline \multicolumn{5}{|l|}{ \% Difference from Salaried Worker } \\
\hline $\begin{array}{l}\text { Incorporated } \\
\text { Unincorporated }\end{array}$ & $\begin{array}{l}1 \% \\
0 \%\end{array}$ & $\begin{array}{l}12 \% \\
-3 \%\end{array}$ & & \\
\hline Self-Employed in Nonroutine Industry & & & $-4 \%$ & $11 \%$ \\
\hline Self-Employed & & & $2 \%$ & $-3 \%$ \\
\hline \multicolumn{5}{|l|}{ Sample } \\
\hline $\begin{array}{l}\text { AFQT } \\
\text { Illicit Index }\end{array}$ & $\begin{array}{c}\text { AFQT }<=50 \text { or } \\
\text { Illicit }<=0\end{array}$ & $\begin{array}{c}\text { AFQT }>50 \& \\
\text { Illicit }>0\end{array}$ & $\begin{array}{c}\text { AFQT }<=50 \text { or } \\
\text { Illicit }<=0\end{array}$ & $\begin{array}{c}\text { AFQT }>50 \& \\
\text { Illicit }>0\end{array}$ \\
\hline Pseudo R-squared & 0.016 & 0.017 & 0.017 & 0.018 \\
\hline Observations & 13269 & 4210 & 13269 & 4210 \\
\hline
\end{tabular}

Note: This table reports median regressions of the change in annual earnings on the change in employment type for white males working full-time, full-year using data from the NLSY79 for years 1982 through 2012. In regressions (1) versus (2) and (3) versus (4), the sample is split between individuals who have (a) AFQT $<50$ or Illicit $<0$ and (b) the smart and illicit with AFQT $>50$ and $>0$. The Illicit Index, which was computed in 1980, measures the degree to which an individual engaged in an array of aggressive, risk-taking, and disruptive activities and has a median value of zero. AFQT is a measure of cognitive ability and has a median value of 50 . In regressions (1) and (2), the main explanatory variables are the change in the incorporated and the unincorporated status over the past two years, where incorporated and unincorporated employment status are defined by the first year of the self-employment spell. A self-employment spell is the full set of consecutive years in which a person is self-employed (either incorporated or unincorporated). In regressions (3) and (4), the main explanatory variables are (a) the change in self-employment status interacted with a dummy variable of whether the business is in Nonroutine Cognitive Industry or not, (b) the change in self-employment status, and (c) a dummy variable of whether the person works in a Nonroutine industry or not. A Nonroutine Cognitive industry is an industry that demands both above average values of Nonroutine Analytical skills (analytical flexibility, creativity, reasoning, and generalized problem-solving) and Nonroutine Direction, Control, Planning skills (complex interpersonal communications such as persuading, selling, and managing others) from its workers. The change in self-employment status equals one if the person switches from salaried work in $\mathrm{t}-2$ to self-employment in $\mathrm{t}$. The statistics for \% Difference from salaried workers are calculated for the corresponding group of salaried workers, e.g., in regression (2), the change in annual earnings is computed relative to the median among salaried workers with AFQT $>50$ and Illicit > 0 , and in regression (4), then computations are done relative to the median among salaried workers with AFQT $>50$ and Illicit $>0$ in Nonroutin Cognitive Industries. All specifications control for experience and time effects. Heteroskedasticity robust standard errors clustered at the year-level are in parentheses, where $*, * *$, and $* * *$ indicate significance at the $10 \%, 5 \%$, and $1 \%$ levels respectively. 


\begin{tabular}{lcc}
\hline \hline & Coefficient of Variation \\
\cline { 2 - 3 } & CPS Panel & NLSY79 \\
\cline { 2 - 3 } Incorporated & $0.157^{* * *}$ & $0.181^{* * *}$ \\
& $(0.007)$ & $(0.027)$ \\
Unincorporated & 0.176 & $0.213^{* * *}$ \\
& $(0.138)$ & $(0.017)$ \\
Constant & $0.197^{* * *}$ & $0.301^{* * *}$ \\
& $(0.001)$ & $(0.047)$ \\
& 67533 & 3120 \\
Observations & 0.003 & 0.124 \\
R-square & & \\
\hline Note: This table reports regressions of the coefficient of variation per person-employment spell on \\
employment type. For the CPS and NLSY79 samples, we compute the coefficient of variation over \\
employment spells, where we define an employment spell as an individual working for two or more \\
consecutive years either as a salaried worker or as self-employed. We define a self-employment spell \\
$\begin{array}{l}\text { as an individual being self-employed (either incorporated or unincorporated) for one or more } \\
\text { consecutive years. Thus, many individuals have more than one employment spell. We control for the }\end{array}$ \\
$\begin{array}{l}\text { length of the employment spell. Standard errors are in parentheses, corrected for heteroskedasticity, } \\
\text { and clustered at the individual level in the NLSY79 regression. The symbols ***, **, and * signify } \\
\text { significance at the one, five, and ten percent levels respectively. }\end{array}$ \\
\hline \hline
\end{tabular}


Figure 1: Years as Unincorporated Before a Business Owner Incorporates, NLSY79

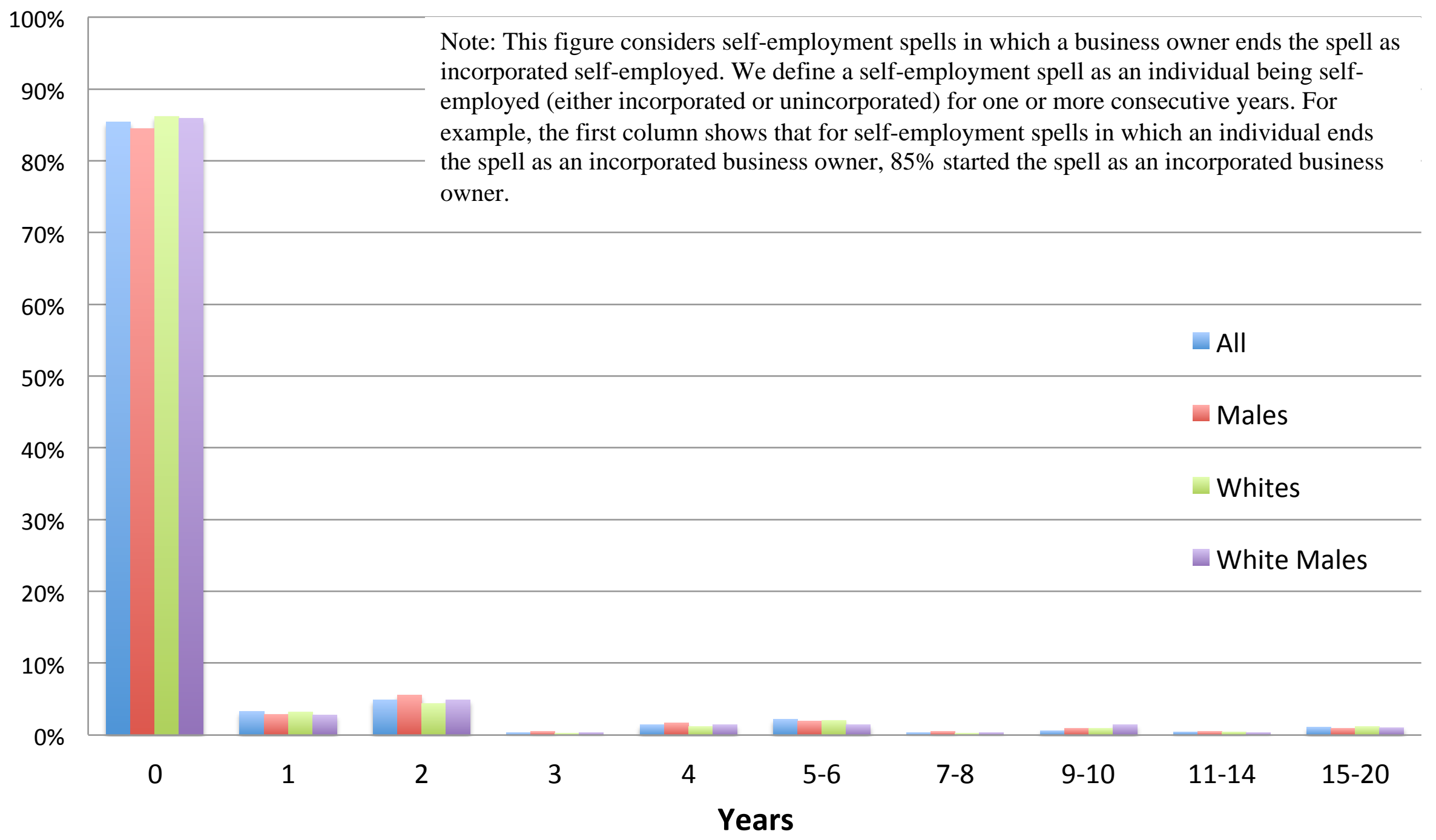


Figure 2: Years as Incorporated Before a Business Owner Unincorporates, NLSY79

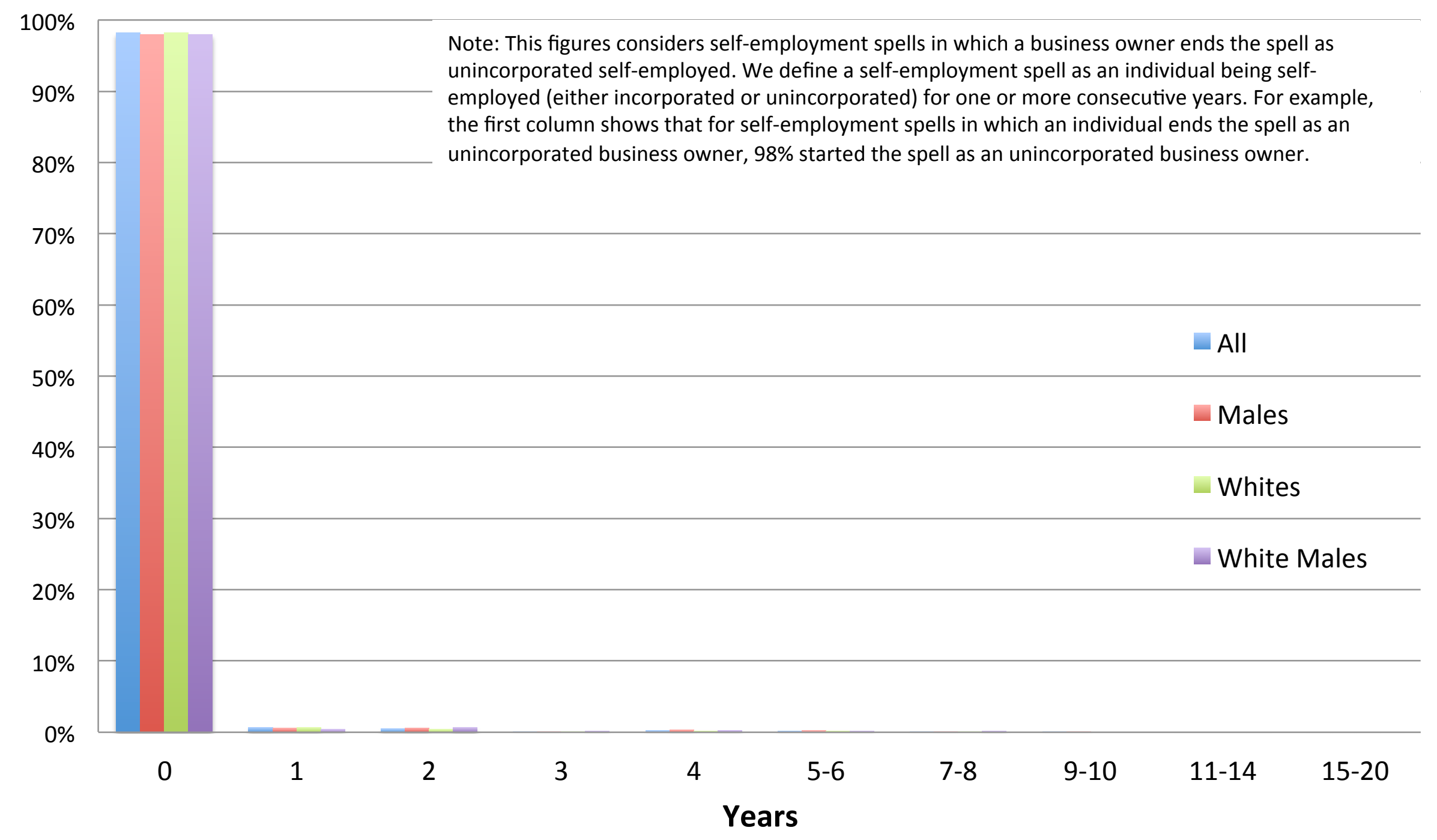




\section{Figure 3a: Annual Earnings Gap between Incorporated and Salaried, NLSY79}

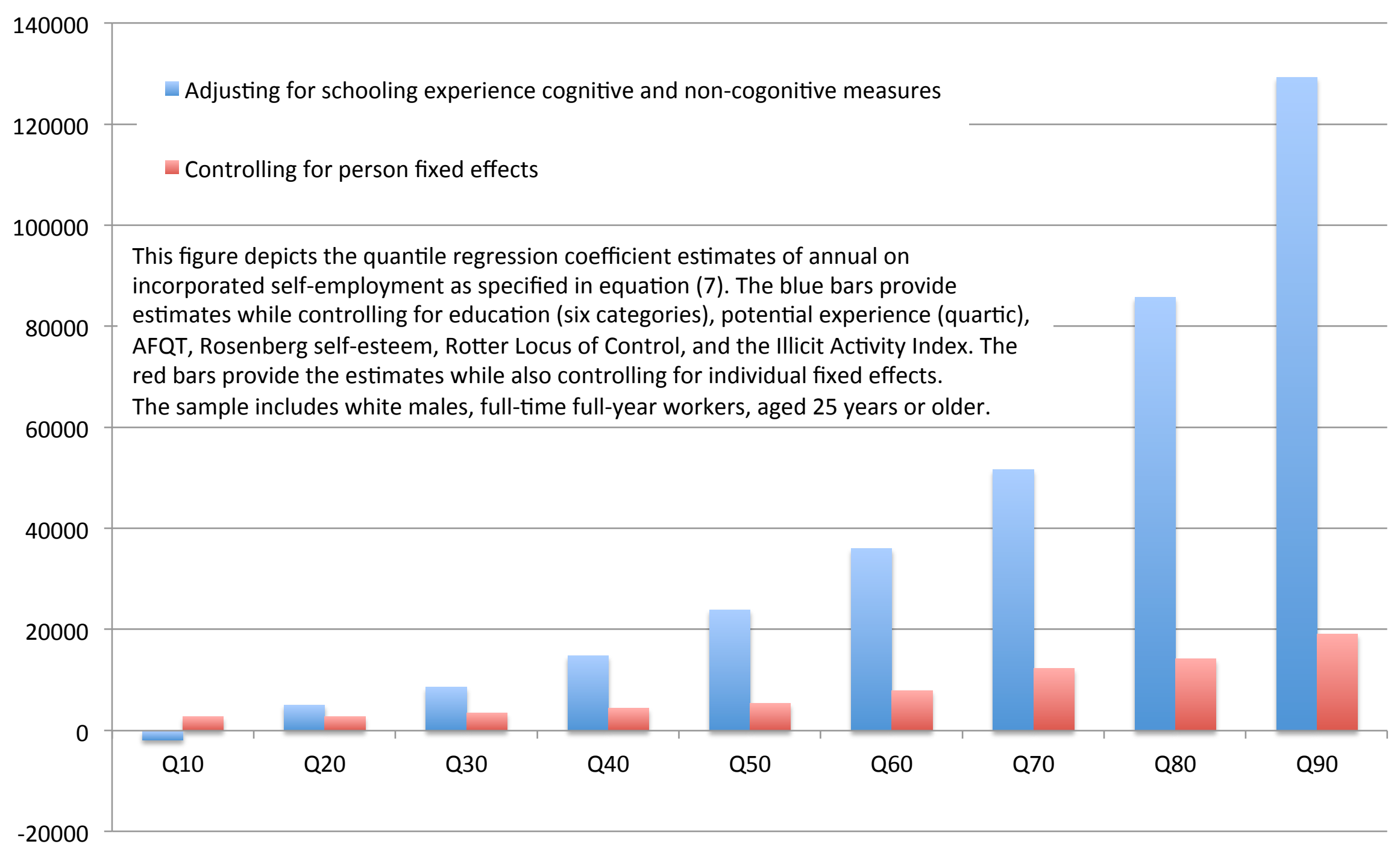




\section{Figure 3b: Annual Earnings Gap between Unincorporated and Salaried, NLSY79}

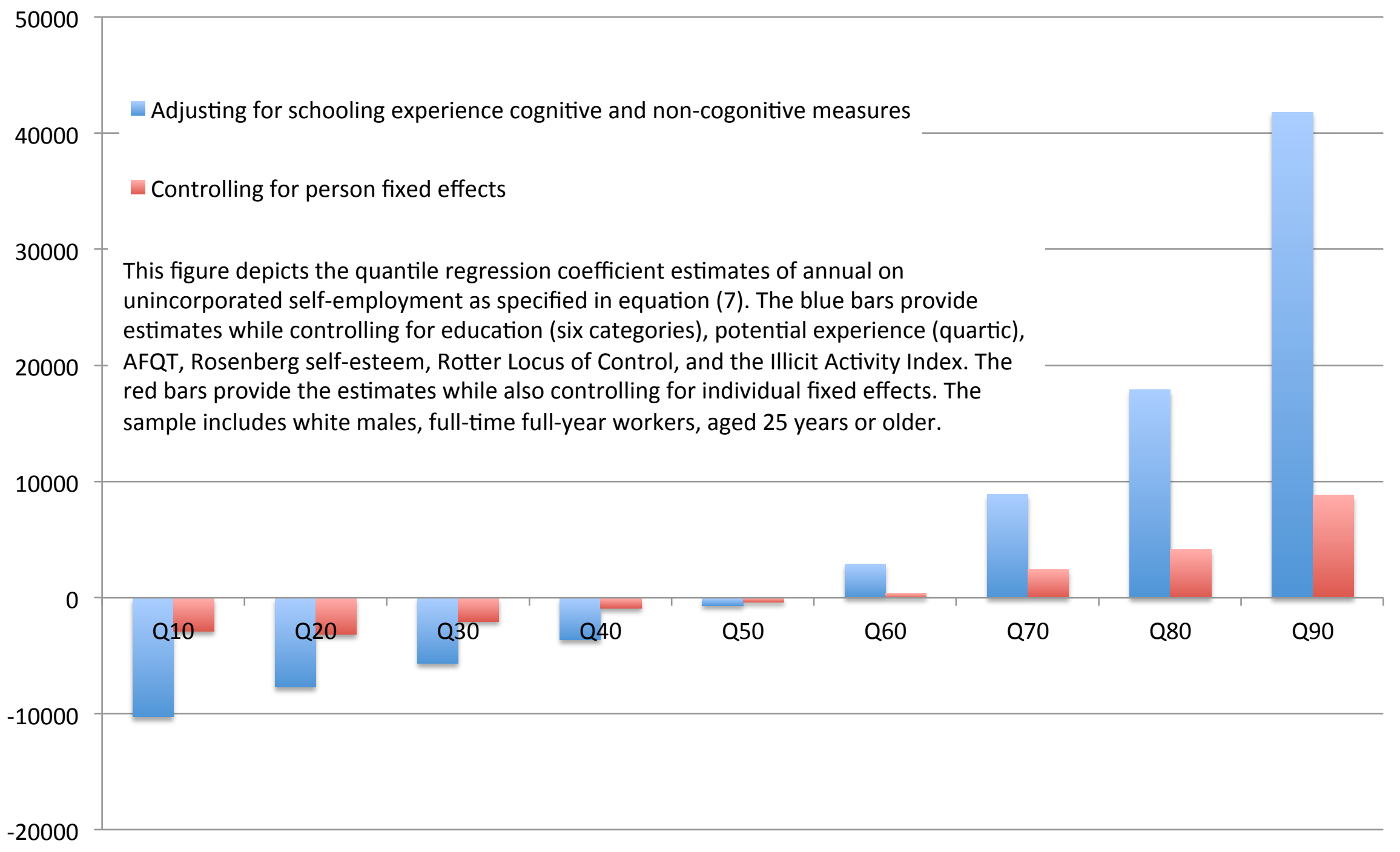

